NBER WORKING PAPER SERIES

\title{
THE QUANTITY AND QUALITY OF LIFE AND \\ THE EVOLUTION OF WORLD INEQUALITY
}

\author{
Gary S. Becker \\ Tomas J. Philipson \\ Rodrigo R. Soares \\ Working Paper 9765 \\ http://www.nber.org/papers/w9765
NATIONAL BUREAU OF ECONOMIC RESEARCH 1050 Massachusetts Avenue
Cambridge, MA 02138
June 2003

An earlier version of this paper circulated under the title "Growth and Mortality in Less Developed Nations." We benefited from comments of seminar participants at the 2002 AEA Meetings (Atlanta) and the World Bank. Becker and Philipson received support from the George J. Stigler Center for The Study of The Economy and The State. Becker received support from The John M. Olin Foundation and the NIHCD (Grant \#5401). The views expressed herein are those of the authors and not necessarily those of the National Bureau of Economic Research.

(C2003 by Gary S. Becker, Tomas J. Philipson, and Rodrigo R. Soares. All rights reserved. Short sections of text not to exceed two paragraphs, may be quoted without explicit permission provided that full credit including (C) notice, is given to the source. 
The Quantity and Quality of Life and the Evolution of World Inequality

Gary S. Becker, Tomas J. Philipson, and Rodrigo R. Soares

NBER Working Paper No. 9765

June 2003

JEL No. I1, I3, J1, O1

\section{$\underline{\text { ABSTRACT }}$}

Lack of income convergence for the world as a whole has led to concerns about the impact of globalization of markets on world inequality. GDP per capita is usually used to proxy for the quality of life of individuals living in different countries. However, well-being is also affected by quantity of life, as represented by longevity. This paper incorporates longevity into an overall assessment of the evolution of cross-country inequality. The absence of income convergence noticed in the growth literature is in stark contrast with the reduction in inequality after incorporating recent gains in longevity. The paper computes a "full" income measure to value the life expectancy gains experienced by 49 countries between 1965 and 1995. Countries starting with lower income tended to grow more in terms of "full" income than countries starting with higher income. The average growth rate of "full" income is about $140 \%$ for developed countries, compared to $192 \%$ for developing countries. Additionally, we decompose changes in life expectancy into changes attributable to thirteen broad groups of causes of death. Infectious, respiratory and digestive diseases, congenital and perinatal conditions, and "ill-defined" conditions are responsible for most of the mortality convergence observed between 1965 and 1995.

Gary S. Becker Department of Economics University of Chicago

1126 E. 59th Street

Chicago, IL 60637

Rodrigo R. Soares

Department of Economics

University of Maryland

3105 Tydings Hall

College Park, MD 20742
Tomas J. Philipson

The Irving B. Harris Graduate School of Public Policy Studies

University of Chicago

1155 E. 60th Street, Suite 112

Chicago, IL 60637 


\section{Introduction}

Lack of income convergence for the world as a whole has led many people to be worried about the impact of globalization of markets on world inequality. There is a fear that although countries are getting richer, many developing countries are falling behind. Many African countries, for example, have not experienced a significant growth in per capita income during the last few decades, while OECD countries have grown substantially. The absence of long run growth for some poor countries raises concerns about whether development will reach all societies, or whether it will remain restricted to only some countries.

Although GDP per capita is usually used as a proxy for the quality of life in different countries, material gain is obviously only one of many aspects of life that enhance economic well-being. Overall economic welfare depends on both the quality and the quantity of life: yearly income and the number of years over which this income is enjoyed. Recent estimates suggest that longevity has been a quantitatively important component of the overall gain in welfare in the US during the twentieth century (Nordhaus, 2003; Garrett, 2001; and Murphy and Topel, 2003). For example, Murphy and Topel (2003) estimate that the average annual change in life expectancy in the US between 1970 and 1990 had an aggregate value of approximately \$2.8 trillion. These annual gains corresponded to more than half of real GDP in 1980, and almost the same as real consumption in that same year.

Given the quantitative importance of the value of gains in longevity in the US, one wonders whether longevity gains are also an important part of the overall welfare gains in the rest of the world. Incorporating longevity into an overall assessment of how much cross-country inequality has grown may be important, as the absence of income convergence noticed in the growth literature is in stark contrast with the evidence from changes in life expectancy. As we show in this paper, there has been considerable longevity-convergence: in the last 50 years, countries starting with modest longevity levels experienced life expectancy gains significantly larger than countries starting with high longevity levels. 
This suggests that cross-country comparisons of changes in income per capita may be misleading as indicators of changes in economic well-being. This paper tries to account for the impact of longevity on the evolution of welfare across countries during the last few decades. The use of per capita income to evaluate welfare improvements assumes that it reflects the level of economic welfare enjoyed by the average person. We extend the income accounts to incorporate survival rates throughout a person's life. In particular, we interpret per capita income as the income that the average individual in a country would enjoy throughout his life, and interpret the survival rates for different ages on a given year as determining the survival function of this average individual. This allows us to analyze the impact of changes in survival probabilities on the welfare of this hypothetical individual.

We use our longevity-adjusted income measure to reconsider what happens over time to cross-country convergence and inequality. Our discussion refers to inequality across different societies, as measured by differences in welfare of this hypothetical individual. We do not consider the individual-level evolution of world inequality, as recently done, for example, by Sala-i-Martin (2002).

This methodology is an extension of the original work of Usher (1973), which was developed further by Rosen (1988). The approach allows us to give monetary values to the longevity gains experienced by different countries between 1965 and 1995. These estimated values, together with traditional per-capita income data, are then used to assess the evolution of welfare in different countries, and the evolution of differences in welfare across countries. Briefly, we compute the income gains that would represent welfare improvements equivalent to the observed longevity gains. We analyze how the growth in this "full" income, including both income per year and years enjoyed, changes the traditional results regarding cross-country convergence. Our results indicate that countries starting with lower income tended to grow more in terms of the "full" income measure than countries starting with higher income. Using parameters from the value of life literature, we estimate the per capita value of the longevity gains in terms of annual income to be equivalent to $28 \%$ of the observed growth in per capita income for the US, and more than 1.5 times the growth in per capita income for less-developed countries, such as El Salvador, Chile, and Venezuela. More generally, the growth rate of the "full" 
income measure in the thirty-year period examined has an average of $140 \%$ for developed countries and 192\% for developing countries.

We also disaggregate mortality data by causes of death to try to understand the determinants of the cross-country convergence in life expectancy observed in the three decades between 1965 and 1995. For each group of causes of death, we compute a counterfactual measure of the mortality rate that would be observed in 1995 had mortality rates by all causes but the one in question remained at their 1965 values. This approach allows us to estimate the life expectancy gain attributable to reductions in mortality by each specific cause of death. We show that changes in mortality due to infectious, respiratory and digestive diseases, congenital and perinatal conditions, as well as "illdefined" conditions are the most important factors determining the convergence in life expectancy. In other words, mortality of these causes of death fell more rapidly in poor than in rich countries. At the same time, changes in mortality due to nervous system, senses organs, heart and circulatory diseases worked against convergence, as mortality for these causes fell more rapidly in rich rather than in poor countries. The large changes in mortality observed in the developing world are consistent with the interpretation that poor countries absorbed technology and knowledge previously available in rich countries, at relatively low costs, while most of the changes in mortality in developed countries took advantage of recent developments on the frontier of medical technology.

The structure of the paper is outlined as follows. Section 2 documents the recent trends in longevity and per capita income growth, particularly the convergence in longevity and the lack of convergence in per capita income. Section 3 discusses the methodology used in the paper, and the parameterization and calibration of the model. Section 4 uses these estimates to compute the value of welfare gains and the change in inequality across countries, once life expectancy is accounted for. Of particular importance here is the fact that poorer countries have gained more in longevity than richer countries, so that the change in inequality in income per capita underestimates the convergence in overall economic welfare. Section 5 decomposes the changes in life expectancy into changes attributable to thirteen broad groups of causes of death. It shows that recent patterns of mortality change differ greatly between developed and developing countries. Also, it shows that a particular group of diseases is responsible for most of the 
mortality convergence observed in the last thirty years. Lastly, section 6 summarizes the main results and concludes the paper.

\section{The Basic Trends: Post-War Convergence in Longevity and Divergence in Income}

The lack of income convergence across countries has been extensively documented. This section reviews the evidence, calculates usual indicators of income convergence for our data set, and analyzes whether there is cross-country convergence in life expectancy. We concentrate on the changes observed between 1965 and 1995. The mortality data are from the World Health Organization Mortality Database. Income figures are from the Penn World Tables, version 6.0. The definition of the variables and the countries included in the sample are contained in the Appendix. ${ }^{1}$

\subsection{Lack of Income Convergence}

A vast literature has investigated whether poor countries tend to grow faster than rich ones. ${ }^{2}$ All these studies give virtually the same results. ${ }^{3}$ Simple Gini coefficients, regressions of growth rates on initial or final period incomes, standard deviations, coefficients of variation, or indices of rank concordance do not show any evidence of absolute convergence across countries (Park, 2000; Cannon and Duck, 2000; Boyle and McCarthy, 1999; Quah, 1996; Barro and Sala-i-Martin, 1995; and Parente and Prescott, 1993). If anything, evidence suggests that rich countries tend to grow somewhat faster than poor ones.

\footnotetext{
${ }^{1}$ The sample includes 49 countries. These are the countries for which detailed mortality data by causes of death are available for 1965 and 1995. Since this information is used for the calculations performed later on in the paper, for consistency, we keep this same sample throughout. None of the results reported in this section depend in any way on the sample. If anything, results tend to be stronger when a broader group of countries is used (available from the authors upon request).

${ }^{2}$ See, for example, the original contributions of Barro and Sala-i-Martin (1992) and Mankiw et al (1992). For a discussion of the main results of this literature, see de la Fuente (1997), Quah (1996), and Barro and Sala-i-Martin (1995).

${ }^{3}$ There is still controversy in relation to how convergence should be measured: on beta and sigma convergence see Barro and Sala-i-Martin (1995), on Galton's fallacy see Cannon and Duck (2000).
} 
Our data replicates the most commonly cited results of this literature. The income statistic used is GDP per capita adjusted for terms of trade in international prices (from now on, GDP). Table 1 presents standard deviations and coefficients of variation for GDP and $\ln (\mathrm{GDP})$, in 1965 and 1995. All measures of dispersion either stay constant or increase. Overall, the cross-country dispersion of income does not seem to have decreased in the thirty years between 1965 and 1995.

But, since Galton, it is well known that a falling variance over time - i.e. reduced cross-sectional inequality - is not the same thing as regression to the mean - i.e. poor countries growing faster than rich ones. To explore this point, Figure 1 shows the result of a regression of the increase in the natural logarithm of GDP between 1965 and 1995 (or growth rate of GDP, $\ln ($ GDP95/GDP65)), on the natural logarithm of the initial income level $(\ln ($ GDP65)). The coefficient of $\ln ($ GDP65) is negative $(-0.13)$, but not statistically significant. ${ }^{4}$ Besides, the correlation between the two variables is very small, as reflected in the $\mathrm{R}^{2}$ of only 0.04 . Poor countries do not seem to grow faster than rich ones. So evidence from our data set replicates the well-known result that there is no income convergence across countries, whether interpreted as falling cross-sectional inequality or growth rates conditional on initial levels.

\subsection{Longevity Convergence}

In contrast with the evidence for per capita income, convergence in life expectancy has been taking place. Countries starting with low longevity tended to gain more in life expectancy than countries starting with high longevity. We use the same techniques common to the growth convergence literature to demonstrate this for life expectancy at birth.

Table 1 presents standard deviations and coefficients of variation for life expectancy at birth (from now on, Life), in the years 1965 and 1995. Both measures of dispersion fall greatly in this thirty-year period. The coefficient of variation falls by $44 \%$,

\footnotetext{
${ }^{4}$ As discussed by Friedman (1992) in another context, zero-mean measurement error in the initial period income tends to generate a spurious negative correlation between income per capita in 1965 and growth rate in the following thirty years. This correlation biases the coefficient of the regression towards negative values, artificially increasing the measured degree of convergence. Nevertheless, even with the bias
} 
from 0.075 to 0.042 . There has been a significant reduction in the cross-country dispersion of longevity between 1965 and 1995 .

Figure 2 presents the result of a regression of the gains in life expectancy at birth between 1965 and 1995 (Life95 - Life65) on the initial level of life expectancy (Life65). The coefficient on Life65 is negative and statistically significant at any conventional significance level. ${ }^{5}$ The point estimate implies that, on average, each additional 10 years of life expectancy in 1965 represented a reduction of more than 6 years in life expectancy gains in the following 30 years.

\subsection{The Changing Relation between Income and Longevity}

The previous evidence shows that, while there is no convergence in per capita income across countries, there is convergence in longevity. Since at any point in time there is a positive correlation between longevity and per capita income, this crosssectional relation must be shifting over time.

For given levels of income, longevity has been rising, and this increase has been greater for poor countries. The shift in this cross-sectional relation was first noticed by Preston (1975), who analyzed data between 1930 and 1960. He showed that, holding income constant, the shift in the longevity-income profile represented gains of up to 15 years in life expectancy. Our data shows that this phenomenon is still taking place. Figure 3 plots life expectancy levels for 1965 and 1995 against per capita GDP for the same years, and fits a logarithm function to each year. For constant levels of income, life expectancy has been rising. This rise has been more than 5 years for poor countries. ${ }^{6}$

towards convergence, it is not uncommon for one to obtain a positive and marginally significant coefficient in this regression when a larger sample of countries is used.

${ }^{5}$ The point raised in footnote 4 does not apply here. It is widely accepted that life expectancy numbers for developing countries are probably overestimated, since number of deaths in remote areas (where there is not much presence of the state) are likely to be underreported. In this case, measurement error in the initial period does not have zero mean. Also, it seems reasonable to assume that record keeping practices have improved in the last thirty years, and evidence presented in section 5 supports this idea. If that is the case, developing countries would have a systematically positive measurement error in life expectancy, and this error would be systematically larger in 1965. Therefore, the regression of changes in life expectancy on initial levels would bias the convergence coefficient towards positive values. True convergence should be even higher than the one measured in Figure 2. The measurement error in life expectancy is likely to work against all the main results discussed in the paper.

${ }^{6}$ Again, these features of the data are intensified when a larger sample of countries is used. 
Measurement error could potentially explain part of this shift. If life expectancy is determined by permanent income, but we observe permanent income plus a transitory error, a way to estimate the "permanent" slope would be to compare life expectancy and income at the means in each year. Assuming a stable 'permanent income-life expectancy' profile throughout the period, we can calculate the largest life expectancy gain that could be potentially explained by changes in income. This strategy attributes the shift to measurement error, and implicitly assumes that all changes in life expectancy were determined by changes in permanent income.

By applying this methodology to our dataset, we find the coefficient of the relation between life expectancy and the natural logarithm of income per capita to be 9.7, more than two times larger than the coefficients estimated in the regressions from Figure 3. But additional evidence suggests that measurement error cannot account for the whole story. First, this estimated coefficient generates systematic differences in prediction errors between developed and developing countries that are not compatible with the simplest version of the measurement error hypothesis: life expectancy gains are, on average, underestimated for developing countries and overestimated for developed countries. If measurement error in income was behind the observed shift, we should expect just the opposite. In addition, the cross-sectional relationship between life expectancy and other demographic variables - such as educational attainment and fertility - is more stable over time (see, for example, Soares, 2003). To the extent that these variables are usually thought to be measured less precisely than income, it is difficult to argue that the entire shift in the income-life expectancy profile should be attributed to measurement error.

Together with the evidence presented in Preston (1975), Figure 3 suggests that the cross-sectional relation between income and longevity has been shifting constantly since the beginning of the twentieth century. Longevity gains have been taking place in all income ranges, with particular intensity in medium and lower levels. In fact, this changing relationship explains the contradicting trends in terms of life expectancy convergence vis-à-vis income convergence. If we only consider the component of the change in life expectancy explained by changes in income, there is no convergence. 
This point is explored in Figure 4, where we simulate the life expectancy level that would be observed in 1995, had the 1965 income-life expectancy profile remained stable throughout the period. In other words, using the regression estimated in Figure 3, we simulate the 1995 life expectancy level as: $L^{\prime}{ }_{95}=L_{65}+4.05\left(\ln y_{95}-\ln y_{65}\right)$, where $L$ denotes life expectancy at birth, and $y$ denotes income per capita. This simulates the life expectancy that would be observed in 1995 if all the changes in this variable between 1965 and 1995 were driven by changes in income, with the 1965 income-life expectancy profile remaining stable. Figure 4 shows that, once we look only at the component of life expectancy changes explained by changes in income, there is no convergence. If anything, the Figure suggests that the dimension of life expectancy correlated with income tended to increase cross-country dispersion. Convergence in life expectancy seems to be driven by changes that are actually orthogonal to changes in income.

Since life expectancy is an important dimension of welfare, the evidence discussed in this section indicates that it could be misleading to analyze the evolution of a country's economic well-being - or the difference in well-being across countries - based solely on income indicators. In the next section, we develop a methodology to incorporate longevity into the analysis of the cross-country evolution of welfare and inequality.

\section{Adding the Two Trends: Monetizing the Value of Longevity Gains}

To incorporate life expectancy gains into the analysis, we must be able to express these gains and income gains into the same units. With this goal, we draw from the literature on the economic value of risks to life (for an overview of this literature, see Viscusi, 1993). Estimates for the US suggest that gains in longevity between 1970 and 1990 represented welfare improvements comparable to the material gains observed in the same period, and that historical reductions in mortality were also major sources of welfare improvements (see Cutler and Richardson, 1997; Nordhaus, 2003; Murphy and Topel, 2003; and Garrett, 2001). 


\subsection{Converting Longevity Gains into their Income Value}

Previous work of Usher (1973), Rosen (1988), and Murphy and Topel (2003), derive the utility parameters of interest that determine the marginal willingness to pay for longevity gains. Given the infra-marginal changes in longevity and income observed during the long time period we analyze, we derive the analog infra-marginal expressions that do not rely on marginal approximations. Consider the indirect utility function $V(Y, S)$ of an individual with survival function $S$ and lifetime full income $Y:^{7}$

$$
V(Y, S)=\max \int_{0}^{\infty} \exp (-\rho t) S(t) u(c(t)) d t
$$

subject to

$$
Y=\int_{0}^{\infty} \exp (-r t) S(t) y(t) d t=\int_{0}^{\infty} \exp (-r t) S(t) c(t) d t
$$

where $y(t)$ is income at age $t, c(t)$ consumption at $t$, and $r$ is the interest rate; and where the budget constraint assumes the existence of a complete contingent claims market.

Now consider a given country at two points in time, $\tau$ and $\tau+\Delta \tau$, with lifetime income and survival functions denoted $Y_{\tau}$ and $S_{\tau}$, and $Y_{\tau+\Delta \tau}$ and $S_{\tau+\Delta \tau}$. We are interested in the infra-marginal income that would give a person in this country the same utility level observed in period $\tau+\Delta \tau$, but with the mortality rates observed in period $\tau$. This income equivalent compensation $E$ would satisfy

$$
V\left(E+Y_{\tau+\Delta \tau}, S_{\tau}\right)=V\left(Y_{\tau+\Delta \tau}, S_{\tau+\Delta \tau}\right)
$$

Figure 5 illustrates the exercise in terms of indifference curves of the indirect utility function on the $(Y, T)$ plane, for the case of a deterministic lifetime equal to $T$. We slide in the indifference curve of period $\tau+\Delta \tau$ to the longevity observed in period $\tau$; the income at that point is $E+Y_{\tau+\Delta \tau}$.

More formally, we abstract from life cycle considerations by assuming that $r=\rho$, $y(t)$ is constant $(y(t)=y$ ), and the individual has access to a fair insurance (as expressed

\footnotetext{
${ }^{7}$ When the context is clear, we save on notation by writing the survival function as $S$, instead of $S(t)$.
} 
in the budget constraint). With these assumptions, it is well known that optimal consumption $c(t)$ is also constant, so that $c(t)=c=y$. This implies that the indirect utility function can be expressed in terms of the yearly income $y$ as

$$
V(y, S)=u(y) \int_{0}^{\infty} \exp (-r t) S(t) d t
$$

Define $A(S)$ as the value of an annuity based on the survival function $S$, such that $A(S)=\int_{0}^{\infty} \exp (-r t) S(t) d t$. If $e$ is the yearly - as opposed to lifetime - income that compensates for lower longevity in a manner similar to before, $e$ satisfies

$$
u\left(e+y_{\tau+\Delta \tau}\right) A\left(S_{\tau}\right)=u\left(y_{\tau+\Delta \tau}\right) A\left(S_{\tau+\Delta \tau}\right) .
$$

With a first order Taylor expansion of $u\left(\right.$.) around $y_{\tau+\Delta \tau}$ to approximate $u\left(e+y_{\tau+\Delta \tau}\right)$, one obtains $u\left(e+y_{\tau+\Delta \tau}\right) \approx u\left(y_{\tau+\Delta \tau}\right)+u^{\prime}\left(y_{\tau+\Delta \tau}\right) e$. Substituting for $u\left(e+y_{\tau+\Delta \tau}\right)$ from expression ( $\left.3^{\prime}\right)$ above and rearranging terms, yields:

$$
\begin{aligned}
& e=\frac{u\left(y_{\tau+\Delta \tau}\right)}{u^{\prime}\left(y_{\tau+\Delta \tau}\right)}\left[\frac{A\left(S_{\tau+\Delta \tau}\right)-A\left(S_{\tau}\right)}{A\left(S_{\tau}\right)}\right], \\
& \text { or } \\
& \frac{e}{y_{\tau+\Delta \tau}}=\frac{1}{\varepsilon\left(y_{\tau+\Delta \tau}\right)}\left[\frac{A\left(S_{\tau+\Delta \tau}\right)-A\left(S_{\tau}\right)}{A\left(S_{\tau}\right)}\right] ;
\end{aligned}
$$

where $\varepsilon($.$) is the elasticity of the instantaneous utility function in relation to its argument.$

Though we will not make use of linear approximations in our empirical analysis, this expression neatly illustrates the main determinants of the value of longevity gains. In short, the value rises with the degree of inter-temporal substitution and the percentage (discounted) longevity gain. More specifically, two dimensions summarized in this expression will be very important in our analysis: the level of income (or consumption) throughout life (term outside brackets), and the size and moment of the reductions in mortality (term inside brackets). Whenever income and longevity are positively correlated across countries, the willingness to pay for an increase in life expectancy will 
generally have two offsetting components. Richer countries attach more value to given longevity gains (higher $u\left(y_{\tau+\Delta \tau}\right) / u^{\prime}\left(y_{\tau+\Delta \tau}\right)$ ), and countries with higher longevity attach less value to given absolute longevity gains (higher $A\left(S_{\tau}\right)$; see Dow et al, 1999). The effect of income comes from the fact that marginal extensions in life expectancy are more valuable the higher is consumption in this extended lifetime, or, in other words, the higher is the income level.

Income can be used to measure material improvements only with a set of assumptions that justify using a single number to portray changes in a country's welfare. Similar simplifying assumptions are needed to measure the material value equivalent to the life expectancy gains observed in a certain period. More precisely, we interpret per capita income from national accounts as the income that the average individual would enjoy throughout his life, and use survival rates for different ages in a given year to determine the survival function this individual would experience. From now on, when talking about economic welfare, we refer to this hypothetical individual, who would face the survival probabilities corresponding to the country's cross-sectional life expectancy at birth, and would earn in every period of life an income equal to the country's per capita GDP in that year. This allows for the calculation of the value of gains in life expectancy using only national income and mortality statistics widely available. For this same reason, the usual critiques of GDP as a measure of full income - due to the fact that it does not incorporate value of leisure, household production, and non-traded goods also apply to our methodology. In fact, what we do is to try to fill in one of these gaps.

Our argument is similar to the one contained in the usual growth discussions based on income alone, as they too implicitly assume that GDP per capita reflects in some way the level of economic welfare enjoyed by the average person. We just extend this interpretation to take into account survival rates across the average person's life. This methodology allows us to discuss the evolution of welfare inequality across countries, by analyzing the changes in welfare of this representative individual. We do not discuss the individual-level evolution of world inequality, as done, for example, by Sala-i-Martin (2002). 


\subsection{The Income Value of Cause Specific Mortality Reductions}

Consider $K$ competing causes of mortality, represented by the survival functions in $S=S^{l} S^{2} S^{3} \ldots S^{K}=\prod_{k=1}^{K} S^{k}$. Following the same steps as in the previous section, define the value (in annual income) of the longevity gain associated with the $k^{\text {th }}$ cause of death as the $e^{k}$ implicitly determined by the following expression ${ }^{8}$

$$
u\left(e^{k}+y_{\tau+\Delta \tau}\right) A\left(S_{\tau}\right)=u\left(y_{\tau+\Delta \tau}\right) A\left(S^{* k}{ }_{\tau+\Delta \tau}\right),
$$

where

$$
S_{\tau+\Delta \tau}^{* k}=S_{\tau+\Delta \tau}^{k} \prod_{i \neq k} S_{\tau}^{i}
$$

$S^{* k}{ }^{k+\Delta \tau}$ is a counterfactual survival function, simulating the survival function that would exist in period $\tau+\Delta \tau$, had the mortality rates for all causes of death but $k$ remained at their $\tau$ period levels. In other words, it simulates what the survival function in $\tau+\Delta \tau$ would be if only the changes observed in the $k^{\text {th }}$ cause of death had taken place.

This strategy allows the decomposition of the gains in life expectancy observed in any given period into $K$ different causes. But, given that changes in mortality from different causes interact with each other in generating the final survival function, this decomposition does not explain exactly $100 \%$ of the shift in this function when inframarginal changes in mortality are being considered (this is the competing risks nature of mortality rates, as discussed by Dow et al, 1999). Formally, this strategy is a first order decomposition of changes in the survival function into changes in its $K$ components. For marginal changes in $S$ through time, this approach would indeed generate an exact decomposition, as in

\footnotetext{
${ }^{8}$ In terms of the first order approximation using the Taylor expansion, the expression for $e^{k}$ would be

$$
e^{k}=\frac{u\left(y_{\tau+\Delta \tau}\right)}{u^{\prime}\left(y_{\tau+\Delta \tau}\right)}\left[\frac{A\left(S_{\tau+\Delta \tau}^{* k}\right)-A\left(S_{\tau}\right)}{A\left(S_{\tau}\right)}\right] .
$$




$$
\frac{\partial S}{\partial \tau}=\sum_{i=1}^{K}\left[\left(\prod_{k \neq i} S^{k}\right) \frac{\partial S^{i}}{\partial \tau}\right] .
$$

Note that each term in the sum is exactly the change in the survival function due to each cause of death that would be obtained using our counterfactual measure $S{ }^{* k+\Delta \tau}$ : $S_{\tau+\Delta \tau}^{*^{k}}-S_{\tau}=\left(\prod_{i \neq k} S_{\tau}^{i}\right)\left(S_{\tau+\Delta \tau}^{k}-S_{\tau}^{k}\right)=\left(\prod_{i \neq k} S_{\tau}^{i}\right) \Delta S^{k}$. So, with marginal changes in mortality rates, $e=\sum_{k=1}^{K} e^{k}$

But with infra-marginal changes, higher order terms due to the complementary nature of mortality rates are also relevant. Nevertheless, we stick to the first order decomposition of changes in survival functions to simplify the discussion, and because due to the interaction among these higher order terms, it is impossible to attribute their effects to any particular cause of death. ${ }^{9}$

$S^{* k}{ }_{\tau+\Delta \tau}$ allows us to construct a counterfactual life expectancy measure that simulates the life expectancy that would be observed in $\tau+\Delta \tau$ if only the changes in mortality due to the $k^{\text {th }}$ cause of death had actually taken place. As discussed in the empirical section, this counterfactual life expectancy measure can be used to decompose the convergence in life expectancy into $K$ underlying mortality causes, plus a higher order term (due to interactions between different causes of death).

\subsection{Parameterization of the Model}

To calculate the economic value of the longevity gains observed between 1965 and 1995, and decompose it into the value attributable to each different cause of death, we need data on per capita income $(y)$, survival rates $(S)$, and a specific functional form for the utility function $(u()$.$) . Two dimensions of the instantaneous utility function u($.$) are$ relevant. The willingness to pay for extensions in life expectancy is affected both by the substitutability of consumption in different periods of life, i.e. the inter-temporal elasticity of substitution, and by the value of being alive relative to being dead. ${ }^{10}$

\footnotetext{
${ }^{9}$ As discussed in the empirical section, these first order terms account for more than $80 \%$ of the changes in life expectancy in the dataset.

${ }^{10}$ This is related to the state-dependent nature of this problem, and to the normalization of utility in the death state to zero (discussed in detail by Rosen, 1988).
} 
We abstract from leisure throughout the paper, and allow the following functional form for the instantaneous utility function to capture these two different dimensions:

$$
u(c)=\frac{c^{1-1 / \gamma}}{1-1 / \gamma}+\alpha
$$

where $\alpha$ is the parameter that arises from the normalization of utility in the death state to zero, and $\gamma$ is the inter-temporal elasticity of substitution. The parameter $\alpha$ determines the level of annual consumption at which the individual would be indifferent between being alive or dead. If that level were positive, an inter-temporal elasticity $\gamma$ larger than 1 would imply that $\alpha$ would be negative.

The parameter $\alpha$ can be identified from other parameters more commonly estimated in the value of life literature. More precisely, we have that

$$
\varepsilon=\frac{u^{\prime}(c) c}{u(c)}=\frac{c^{1-1 / \gamma}}{\frac{c^{1-1 / \gamma}}{1-1 / \gamma}+\alpha}
$$

and, from this expression, $\alpha=c^{1-1 / \gamma}\left(\frac{1}{\varepsilon}-\frac{1}{1-1 / \gamma}\right)$.

The value of $\varepsilon$ can be estimated from compensating differentials for occupational mortality risks. Murphy and Topel (2003, p.23), using numbers from the literature on occupational risks, estimate $\varepsilon$ to be 0.346 .

A wide range of values is available in the empirical literature on the intertemporal elasticity of substitution. Browning, Hansen, and Heckman (1999, p.614), after exhaustively reviewing the estimates, suggest that the inter-temporal elasticity of substitution for non-durables is probably slightly above 1 .

We use $\gamma=1.25, \varepsilon=0.346$ and $c=\$ 18,000$ to calibrate the value of $\alpha$. The value of consumption is the value of US per capita income in 1990 in our data set, the year in which Murphy and Topel (2003) estimate $\varepsilon$ using US data. Our calculations give a value of $\alpha$ equal to -14.97 . Together with the value of $\gamma$, this means that an individual with 
annual income equal to 241 would be indifferent between being alive or dead. ${ }^{11}$ Following Murphy and Topel (2003), we set interest rates to 3\% per year. ${ }^{12}$

With these values of $\alpha$ and $\gamma$, we can use equation (3') to value the life expectancy gains experienced by the different countries in the thirty year period between 1965 and 1995. With all assumptions, ${ }^{13}$

$$
e=\left[y_{\tau+\Delta \tau}{ }^{1-1 / \gamma} \frac{A\left(S_{\tau+\Delta \tau}\right)}{A\left(S_{\tau}\right)}+\alpha\left(1-\frac{1}{\gamma}\right)\left(\frac{A\left(S_{\tau+\Delta \tau}\right)-A\left(S_{\tau}\right)}{A\left(S_{\tau}\right)}\right)\right]^{\frac{\gamma}{\gamma-1}}-y_{\tau+\Delta \tau} .
$$

Again, $e$ gives the additional flow of annual income that would generate a welfare gain comparable to the one generated by the increase in survival probabilities observed during the period. An analogous expression is used to calculate the annual income value of the reductions in mortality due to each particular cause of death. In this case, we substitute $e$ by $e^{k}$, and $S_{\tau+\Delta \tau}$ by $S^{* k+\Delta \tau}$.

We also use $e$ to calculate what we call the growth rate of the income equivalent compensation, given by $g=\frac{y_{\tau+\Delta \tau}+e}{y_{\tau}}-1$. This concept gives the income growth rate that would have been observed had all the welfare gain in the period taken the form of income growth.

\section{The Effect on World Inequality}

We use expression (11) to calculate the value of the longevity gains observed in 49 countries between 1965 and 1995, and to evaluate the impact of the changes in longevity on cross-country inequality. Per capita income figures are taken from the Penn

\footnotetext{
${ }^{11}$ The lowest value of the GDP per capita variable (adjusted for terms of trade, RGDPTT) in the PWT 6.0 dataset is 275.93, for the Democratic Republic of Congo in 1997. Also, this is the only observation in the whole PWT 6.0 dataset with value below 300 .

${ }^{12}$ When presenting the results, we briefly discuss the effects of assuming a higher interest rate.

13 The formula used in the calculations is a discrete time version of (11). A cleaner version of this expression can be obtained if we use the linear approximation from the Taylor expansion. In this case, we have:$$
e=\left(\frac{\gamma}{\gamma-1}-\frac{\alpha}{y_{\tau+\Delta \tau}{ }^{1-1 / \gamma}}\right)\left(\frac{A\left(S_{\tau+\Delta \tau}\right)-A\left(S_{\tau}\right)}{A\left(S_{\tau}\right)}\right) .
$$

Since we have a closed form solution for $e$, there is no reason to use this simpler linear approximation.
} 
World Tables 6.0. Data are ten-year averages centered in the reference years: 1965 corresponds to the average for the period between 1960 and 1969, and 1995 corresponds to the average between 1990 and 1999 (or years available in these intervals).

Survival rates are constructed using age specific number of deaths and population from the World Health Organization Mortality Database. Mortality rates are assumed to be constant inside the age intervals for which data is tabulated. Figure 6 illustrates the extent of variation in age specific mortality rates in the dataset, by plotting two extreme examples: the survival distribution for Egypt in 1965 (lowest life expectancy at birth in the sample), and the survival distribution for Japan in 1995 (highest life expectancy at birth in the sample).

Table 2 presents the results for the value of longevity gains and the growth rate of the income equivalent compensation, together with other income and life expectancy statistics, using the value of the parameters derived in the previous section. The value of longevity gains is presented in two forms: annual income (e), and total discounted lifetime value $(E){ }^{14}$

Results are presented for individual countries and as un-weighted averages for groups of developed and developing countries. Developed countries include countries from North America, Western Europe, and Australia, New Zealand, and Japan, whereas developing countries include countries from Latin America, Eastern Europe, Southeast Asia, and Africa. ${ }^{15}$

On average, the value of longevity gains in terms of annual income is somewhat higher for developed countries: $\$ 1,747$ against $\$ 1,265$ (in international prices). But the

\footnotetext{
${ }^{14}$ Remember that $E$ is the present discounted value of the flow of income $e$, taking into account both the interest rate and the survival probabilities in the initial period ( $\tau=1965): E=e \int_{0}^{\infty} \exp (-r t) S_{\tau}(t) d t=e A\left(S_{\tau}\right)$.

${ }^{15}$ The classification into groups of developed and developing countries inevitably involves some degree of arbitrariness. We try to do so in a way that does not bias the aggregate results in our favor. If anything, our grouping will work towards reducing longevity convergence between developing and developed countries. This is because our developed countries include countries such as Portugal, Spain, Greece, and Ireland, that were not developed in the 1960's and that experienced impressive life expectancy gains in the period. At the same time, our developing countries include Eastern European countries such as Bulgaria, Czechoslovakia, Hungary, and Romania, that had high life expectancy at 1965 and that experienced virtually no gain in this variable during the following period, partly as a consequence of the collapse of the communist block.
} 
highest values of this variable are in the developing world: Chile, Hong Kong, and Singapore experienced longevity gains with values superior to $\$ 3,200$ in annual income. This gain corresponds to $90 \%$ of the Chilean GDP per capita in 1965, while the gains for Hong Kong and Singapore are more than 118\% of their GDP's per capita in 1965.

Longevity gains are more important for developing countries in terms of average annual value as a percentage of the GDP. These gains correspond to $55 \%$ of the 1965 GDP per capita for the less-developed world, and only $29 \%$ for the developed world. This tendency is reflected in the growth rate of the income equivalent compensation. In this case, since the initial income level is lower for developing countries, the difference between developing and developed countries is reversed: the average growth for developing countries is $192 \%$, against $140 \%$ for developed countries.

This indicates that, unlike income changes, longevity changes since 1965 reduced the disparity in welfare across countries. Figure 7 explores this point further by plotting the growth rate of the income equivalent compensation against the natural logarithm of GDP per capita in 1965. As the Figure shows, the inclusion of life expectancy in the measure of welfare tends to increase the convergence in the period. The coefficient on $\ln$ (GDP65) is negative and statistically significant. Higher income in 1965 is consistently associated with lower growth in "full" income in the thirty-year period between 1965 and 1995. ${ }^{16}$

The ideal independent variable in the right-hand side of this regression should be a measure of "full income in 1965." Since the approach discussed in section 3 does not allow us to calculate the value of given levels of life expectancy, but only the value of changes in life expectancy, we are forced to use the 1965 value of income per capita rather than "full income." Using some measure of full income in this regression would unambiguously increase the degree of convergence since richer countries in 1965 also had higher life expectancy.

\footnotetext{
${ }^{16}$ Using a higher interest rate reduces the overall willingness to pay for reductions in mortality because of the heavier discounting of future gains in longevity. But it does not change the qualitative results regarding convergence. For example, with $\mathrm{r}=0.07$ - roughly the rate of return on capital in the US - the average growth rate of the income equivalent compensation becomes $118 \%$ for developed countries, and $145 \%$ for developing countries. In the cross-country convergence regression, the coefficient on income per capita in 1965 increases slightly in absolute value, to -0.21 (with p-value $=0.02$ ).
} 
These results indicate convergence in welfare, in the sense that countries with higher initial income tended to have significantly lower subsequent welfare gains (in terms of "full income"). Incomes 100\% higher in 1965 were associated, on average, with income equivalent growth rates $20 \%$ lower in the following 30 years. This result is not surprising, given the negative correlation between life expectancy gains and income. As long as the income elasticity of value of life is not much above unity, any value attached to longevity would work towards increasing convergence. Viscusi and Aldy (2003) conclude, from various types of evidence, that this elasticity is less than unity, but their results for countries are greatly affected by a couple of extreme observations for India. Without these observations, Becker and Elias (2003) get an elasticity of about unity.

Figure 8 shows, for each country in the sample, the share of the welfare improvements observed between 1965 and 1995 due to mortality reductions. This share is calculated as value of longevity gains in annual income/(value of longevity gains in annual income + increase in annual income between 1965 and 1995). The average value across countries is $27 \%$, meaning that recent welfare gains due to mortality reductions average about $1 / 3$ of the material gains observed in the same period. In some cases, like Chile, Ecuador, Egypt, El Salvador, and Venezuela, longevity gains have been by far the most important factor in determining the welfare improvements observed after 1965. As the Figure suggests, this share is systematically related to income: on average, poorer countries had a higher share of welfare gains due to longevity increases (the coefficient of a regression of the share of welfare gains due to longevity on $\ln y_{65}$ is equal to -0.079 with p-value $=0.03$ ).

Overall, the evidence shows that longevity changes in the period between 1965 and 1995 worked towards reducing the disparity in welfare across countries. The actual reduction in disparity depends on the specific values of the parameters $\alpha$ and $\gamma$, that is, on the relative importance of quantity and quality of life. But, nevertheless, the qualitative role played by mortality reductions in the process should be obvious.

These results would be even stronger if we accounted for expenditures on health and $R \& D$, because part of the gains in life expectancy is driven by expenditures on health and $R \& D$. Since most of these expenditures are undertaken by the developed world, the share of truly exogenous reductions in mortality is certainly higher for the less-developed 
countries. ${ }^{17}$ Therefore, convergence in welfare would be higher if the endogenous part of longevity gains were netted out.

\section{The Causes of Mortality Convergence}

Cross-country life expectancy convergence would follow if the health production technology were concave, as illustrated by the logarithmic curves in Figure 3. Countries with higher initial mortality then would have larger mortality reductions because they have much higher returns on investments in health than do countries with lower mortality.

However, some evidence hints that this is not the full story. Figure 3 shows a possible shift in the relation between income and life expectancy, suggesting that a considerable part of the changes in longevity is related to technological improvements. Stable concave returns to investments in health cannot account for this evidence, as Figure 4 clearly illustrated. Moreover, since investments in health are much larger for developed than for developing countries - measured either in absolute terms or as shares of income (see footnote 17) - a stable health production function could not explain the convergence in life expectancy, unless returns to investments in health were much higher for the less-developed world.

\subsection{Data}

To understand the nature of the changes in mortality in the developing world, we decompose the gains in life expectancy into different causes of death. The World Health Organization Mortality Database contains number of deaths by cause of death for the years under analysis. Causes of death in the different years are classified according to the current International Classification of Diseases (ICD) code, so data for different periods has to be made compatible by matching codes of the different versions of the ICD. As we

\footnotetext{
${ }^{17}$ For example: in 1995 , health expenditures per capita in the US and Sweden were around US $\$ 4,000$; in the same year, these expenditures were between US\$100 and US\$200 for Mexico, Poland, and Turkey. In terms of share of per capita GDP, this corresponded to $14 \%$ and $9 \%$ for, respectively, US and Sweden, and below 5\% for Mexico, Poland, and Turkey (data from the World Bank Development Indicators). These numbers are representative of the patterns observed in other developed and developing countries.
} 
will be dealing with rather broad groups of causes of death, this will not be much of a problem.

We define the following thirteen groups of causes of death: R01: infectious diseases; R02: neoplasms; R03: endocrine, metabolic and blood diseases, and nutritional deficiencies; R04: mental disorders; R05: diseases of the nervous system and senses organs; R06: heart and circulatory diseases; R07: respiratory and digestive diseases; R08: urinary and genital diseases; R09: abortion and obstetric causes; R10: skin and musculoskeletal diseases; R11: congenital anomalies and perinatal period conditions; R12: ill-defined conditions; and R13: accidents, suicides and homicides. The grouping of the codes from the ICD-6/7 and ICD-9 into these thirteen categories is described in the Appendix.

\subsection{Convergence Decomposition}

To evaluate the contribution of each cause of death to the observed reductions in mortality, we use the counterfactual survival function $S^{* k}{ }_{\tau+\Delta \tau}$ defined in section 3.2. To recapitulate, we construct, for each cause of death, the survival function that would have been observed in 1995 had mortalities of all causes but the one in question remained at their 1965 levels. ${ }^{18}$ Or, in other words, we simulate what mortality levels would have been observed in 1995 if only the changes in one of the causes of death had actually taken place.

With the cause specific survival functions $S^{* k}{ }_{\tau+\Delta \tau}$, we can immediately construct corresponding cause specific counterfactual measures of life expectancy, each one defined as $L_{\tau+\Delta \tau}^{* k}=\int_{0}^{\infty} S_{\tau+\Delta \tau}^{* k}(t) d t . L^{* k}{ }_{\tau+\Delta \tau}$ is the exact analog of $S^{* k}{ }_{\tau+\Delta \tau}$ in terms of life expectancy. For our purposes, it gives the life expectancy that would be observed in 1995 if only mortality rates due to the $k^{\text {th }}$ cause of death had actually changed between 1965 and 1995.

\footnotetext{
${ }^{18}$ Specifically, to compute the survival function $S^{* k}{ }_{95}$, we use age specific mortality rates for the $k^{\text {th }}$ cause of death calculated using 1995 populations and number of deaths, and age specific mortality rates for all the other causes of death using 1965 populations and number of deaths.
} 
This strategy allows the decomposition of the gains in life expectancy observed in the period into the thirteen different groups of causes of death defined before, plus a higher order term (see discussion in section 3.2). Let $L_{\tau}$ denote life expectancy at birth in year $\tau$. Then

$$
\Delta L=\Delta L^{1}+\Delta L^{2}+\ldots+\Delta L^{13}+\Delta L^{H}
$$

where $\Delta L$ is the change in life expectancy observed between 1965 and $1995 ; \Delta L^{k}$, for $k=$ $1, \ldots, 13$, is the change in life expectancy attributable to the $k^{\text {th }}$ cause of death, defined as $\Delta L^{k}=L^{* k}{ }_{95}-L_{65}$; and $\Delta L^{H}$ is the change in life expectancy due to the interaction between mortality changes in the thirteen groups (higher order terms).

Our goal is to decompose the convergence in life expectancy into convergence in mortality in each one of the thirteen causes of death. By definition, the coefficient indicating convergence in life expectancy is given by the coefficient of a linear regression of $\Delta L$ on a constant plus $L_{65}$. Define $X_{65}=\left[\begin{array}{ll}1 & L_{65}\end{array}\right]$, a matrix containing a column of ones, and a column with the life expectancy at birth for the different countries in the sample in 1965 . The convergence coefficient is given by

$$
\beta=\left(X_{65}{ }^{\prime} X_{65}\right)^{-1} X_{65}{ }^{\prime} \Delta L
$$

By substituting $\Delta L$ from expression (12), we can write $\beta=\left(X_{65}{ }^{\prime} X_{65}\right)^{-1} X_{65}{ }^{\prime}\left(\Delta L^{1}+\right.$ $\left.\Delta L^{2}+\ldots+\Delta L^{13}+\Delta L^{H}\right)$. This expression gives a natural decomposition for the convergence coefficient:

$$
\beta=\left(X_{65}{ }^{\prime} X_{65}\right)^{-1} X_{65}{ }^{\prime}\left(\sum_{k=1}^{13} \Delta L^{k}+\Delta L^{H}\right)=\beta^{l}+\beta^{2}+\ldots+\beta^{13}+\beta^{H},
$$

where $\beta^{i}$, for $i=1, \ldots, 13, H$, is the coefficient of the OLS regression of $\Delta L^{i}$ on $X_{65}$.

In words, the coefficient of the regression of changes in life expectancy on initial life expectancy levels can be decomposed into coefficients of regressions of cause specific changes in life expectancy on initial life expectancy levels, plus a residual term 
$\left(\beta^{H}\right)$. That is, convergence in life expectancy is decomposed into convergence attributable to the thirteen underlying causes of death, plus a residual term. This allows us to evaluate the role of different causes of death in generating the observed convergence in life expectancy.

Table 3 presents the results of regressions of the changes in life expectancy attributable to a particular cause of death on the initial life expectancy level (the $\beta^{i}$ coefficients). The Table also presents the $\mathrm{R}^{2}$ of the regressions and the contribution of the specific cause of death to the overall life expectancy convergence $\left(\beta^{i} / \beta\right)$.

The behavior of the regression coefficient is very different across the different causes of death. Out of the thirteen coefficients, six are positive, meaning that the behavior of mortality due to these six causes of death worked against life expectancy convergence. Most of these six "divergent" causes of death had virtually no impact on overall convergence, but two played a considerable role in reducing convergence: mortality by nervous system, senses organs, heart, and circulatory diseases reduced convergence by more than $20 \%$ of its actual value. In the case of nervous system and senses organs diseases, mortality reductions were experienced by both developed and developing countries, but the extent of these reductions was considerably larger for developed countries. In terms of heart and circulatory diseases, mortality reductions were also considerable for developed countries, but basically nonexistent for most of the developing world.

In the case of the causes of death that worked towards increasing convergence, the action is concentrated in a handful of cases: infectious, respiratory and digestive diseases, congenital anomalies, perinatal period conditions, and ill-defined conditions accounted for roughly $110 \%$ of the observed convergence. Among these, respiratory and digestive diseases were by far the most important, accounting for $60 \%$ of the convergence. Note that this group includes infectious diseases related to the respiratory tract, such as pneumonia and influenza, and digestive tract diseases such as appendicitis and cirrhosis. The second most important contribution to convergence comes from "ill- 
defined" causes and conditions. This most likely reflects the relative improvement of medical practice and record keeping behavior in developing countries. ${ }^{19}$

These results support the view that recent reductions in mortality in the developing world have been due in part to the absorption of previously available technologies (for arguments in this direction, see Preston, 1980; and Soares, 2003). The group of infectious, respiratory and digestive diseases, congenital anomalies, and perinatal period conditions includes the types of diseases for which educational health programs and simple interventions can have large beneficial effects. On the other side of the spectrum, developed countries benefited relatively more from reductions in mortality that required new technological developments, relatively costly change of habits, and expensive surgical interventions (heart, circulatory, and nervous system diseases). The concept is of a developed center that generates health and medical knowledge to be absorbed eventually by the underdeveloped periphery.

\subsection{Value of Longevity Gains Decomposition}

Using the methodology described in section 3.2, we decompose the value of life expectancy gains into gains attributable to the thirteen causes of death. The value of life expectancy gains attributable to each particular cause of death is calculated using survival rates which assume that only mortality due to one cause of death changed between 1965 and 1995.

Table 4 presents the total value of longevity gains in the period, repeated from Table 2, and the value attributable to each group of causes of death. Table 5 presents this same information in relative terms: the first column shows the share of the total value of life expectancy gains that is explained by the "first order" decomposition, and the other columns show the share of the explained gain attributable to each disease group (columns

\footnotetext{
${ }^{19}$ The fact that "ill-defined" conditions were relatively more common in developing countries in 1965 tends to underestimate the actual convergence in the other causes of death. This is so because a larger share of the reduction in mortality in developing countries is being attributed to "ill-defined" causes and conditions. Which causes of death suffer the biggest underestimation depends on the correlation between cause of death and misreporting ("ill-defined"). We do not deal with this problem.
} 
R01 to R13 add up to $100 \%) .{ }^{20}$ Results are presented for each individual country and for the groups of developed and developing countries.

Table 4 shows that, even though developing countries gained relatively more in terms of respiratory and digestive diseases, developed countries also gained substantially in absolute terms from reductions in mortality from these causes. And even though the gains in life expectancy from improvements in survival for congenital anomalies and perinatal period conditions were larger for developing countries, the absolute value of these gains was more than two times higher for developed countries.

Overall, Table 4 shows that reductions in death by infectious, nervous systems, senses organs, respiratory and digestive diseases, and congenital anomalies and perinatal period conditions played some role in enhancing welfare both in developed and developing countries. Welfare improvements generated by reductions in mortality due to infectious, respiratory and digestive diseases were higher for developing countries, while welfare improvements generated by reductions in mortality due to nervous system and senses organs diseases and congenital anomalies and perinatal conditions were higher for developed countries. In addition, developed countries experienced some sizeable gains in areas where developing countries did not: neoplasms, heart, circulatory, and accidents, suicides and homicides. At the same time, developing countries appear to have substantially improved their diagnosis and record keeping techniques, which generated a large increase in welfare attributable to reductions in mortality by "ill-defined" causes.

Table 5 translates the numbers of Table 4 into relative terms, giving the share of the gain in welfare attributable to a particular cause. This Table summarizes what types of mortality reductions were more important for each different country. The value of mortality reductions due to respiratory and digestive diseases, congenital anomalies and perinatal period conditions, and ill-defined conditions were the most important ones for developing countries. Similarly, the value of mortality reductions attributable to nervous system, senses organs, heart, circulatory, respiratory, and digestive diseases, congenital

\footnotetext{
${ }^{20}$ Mortality convergence looks at the causes of death for which developing countries (countries with higher mortality) gained more, when measured by absolute changes in life expectancy. These Tables look at the value of these changes in life expectancy, which depend, for each particular country, on the importance of each cause of death in the overall mortality reduction.
} 
anomalies and perinatal period conditions, accidents, suicides, and homicides were the most important ones for developed countries.

\section{Conclusion}

This paper shows that life expectancy gains in the thirty years between 1965 and 1995 have been an important component of improvements in welfare throughout the world. The total lifetime value (willingness to pay) of these gains for an individual being born in 1995 corresponds to more than 3 times the value of GDP per capita for the case of the US, and more than 10 times the GDP per capita for countries like Chile or Egypt. These values correspond to permanent increases of more than $10 \%$ in annual income for the US, and more than 50\% for Chile and Egypt.

We use the estimated value of the longevity gains to compute "income equivalent compensation" measures: the 1995 income that would give individuals the same welfare level observed in 1995, but with mortality levels from 1965. The incorporation of gains in life expectancy into income measures reverses the absence of income convergence found in studies using conventional GDP measures. Countries starting with lower income grew more in terms of this "full" income measure. Growth rates of "full" income for the period average $140 \%$ for developed countries, and 192\% for developing countries.

Finally, mortality data by cause of death are disaggregated to understand the determinants of the cross-country convergence in life expectancy observed between 1965 and 1995. Changes in mortality due to infectious, respiratory and digestive diseases, congenital and perinatal conditions, and "ill-defined" conditions are the most important factors producing the convergence in life expectancy, whereas changes in mortality due nervous system, senses organs, heart and circulatory diseases worked against convergence. This evidence suggests that the large changes in mortality observed in the developing world were due to the absorption of previously available technology and knowledge, while developed countries took advantage of recent advances on the frontier of medical technology.

Assuming that medical advances are available to the whole population of a given country, the American cohort born in 1995 (approximately 3.8 million people) had an 
aggregate expected welfare gain equivalent to $\$ 261$ billions from the mortality reductions experienced by the US between 1965 and 1995. Mexicans born in 1995 (approximately 2.3 million people) had an aggregate expected welfare gain equivalent to $\$ 133$ billions from mortality reductions experienced by Mexico during the same period. These numbers for the cohort born in 1995 correspond to, respectively, 5\% of the total American GDP for 1995, and 27\% of the Mexican GDP for the same year. 


\section{APPENDIX}

\section{A.1 Definition of Variables}

- Income Series: RGDPTT from the Penn World Tables 6.0. Real GDP adjusted for terms of trade. Information from the PWT 5.6 is used to construct the variable for some former Eastern European countries. Values for Northern Ireland and Scotland are estimated as fractions of the United Kingdom variable. Value for 1965 is the average for all years available between 1960 and 1969. Value for 1995 is the average for all years available between 1990 and 1999 .

- Life Expectancy Series: Calculated from the World Health Organization Mortality Database (number of deaths by cause of death and age group, and population by age group). Value for 1965 is the average for all years available between 1960 and 1969. Value for 1995 is the average for all years available between 1990 and 1999. The dataset is available at http://www.who.int/research/en.

\section{A.2 Countries Included in the Sample}

Argentina; Australia; Austria; Barbados; Belgium; Belize; Bulgaria; Canada; Chile; Colombia; Costa Rica; Cuba; Czechoslovakia, Former; Ecuador; Egypt; El Salvador; Finland; France; Germany, Former Fed. Rep.; Greece; Hong Kong; Hungary; Iceland; Ireland; Italy; Japan; Luxembourg; Malta; Mauritius; Mexico; Netherlands; New Zealand; Norway; Philippines; Poland; Portugal; Puerto Rico; Romania; Singapore; Spain; Sweden; Trinidad and Tobago; United Kingdom, England \& Wales; United Kingdom, N. Ireland; United Kingdom, Scotland; United States of America; Uruguay; Venezuela; Yugoslavia, Former.

\section{A.3 Classification of Causes of Death}

See Table A.1. 


\section{References}

Barro, Robert J. and Xavier Sala-i-Martin (1992). Convergence. Journal of Political Economy, 100, n2 (April 1992), 223-51.

Barro, Robert J. and Xavier Sala-i-Martin (1995). Economic Growth. New York, McGraw-Hill, Inc., 1995, 539p.

Becker, Gary S. and Julio J. Elias (2003). "Introducing incentives in the market for live and cadaveric organs." Unpublished Manuscript, University of Chicago.

Boyle, G. E. and T. G. McCarthy (1999). Simple measures of convergence in per capita GDP: A note on some further international evidence. Applied Economic Letters, 1999, $6,343-47$.

Browning, Martin, Lars Peter Hansen, and James J. Heckman (1999). Micro data and general equilibrium models. In: John B. Taylor and Michael Woodford (editors). Handbook of Macroeconomics, V.1A. Elsevier Science B.V., 1999, 543-636.

Cannon, Edmund S. and Nigel W. Duck (2000). Galton's fallacy and economic convergence. Oxford Economic Papers, 52(2000), 415-19.

Cutler, David and Elizabeth Richardson (1997). Measuring the health of the U.S. population. Brookings Paper on Economic Activity: Microeconomics, 1997, 217-71.

de la Fuente, Angel (1997). The empirics of growth and convergence: A selective review. Journal of Economic Dynamics and Control, 21 (1997), 23-73.

Dow, William H., Tomas Philipson, Tomas, and Xavier Sala-i-Martin (1999). Longevity complementarities under competing risks. American Economic Review v89, n5 (December 1999): 1358-71.

Friedman, Milton (1992). Do Old Fallacies Ever Die? Journal of Economic Literature, v30, n4 (December 1992), 2129-32.

Garrett, Allison M. (2001). "Health improvements and the national income and product accounts: 1880 to 1940." Unpublished Manuscript, University of Chicago, January 2001 .

Mankiw, Gregory, Paul Romer, and David N. Weil (1992). A contribution to the empirics of growth. Quarterly Journal of Economics, v107, 1992, 407-37.

Murphy, Kevin M. and Robert Topel (2003). The economic value of medical research. In: Kevin M. Murphy and Robert H. Topel (eds). Measuring the Gains from Medical Research: An Economic Approach. The University of Chicago Press, 2003.

Nordhaus, William D. (1999). The health of nations: The contribution of improved health to living standards. In: Kevin M. Murphy and Robert H. Topel (eds). Measuring the 
Gains from Medical Research: An Economic Approach. The University of Chicago Press, 2003.

Parente, Stephen L. and Edward C. Prescott (1993). Changes in the wealth of nations. Federal Reserve Bank of Minneapolis Quarterly Review, Spring 1993, 3-14.

Park, Donghyun (2000). A note on convergence and the inter-country Gini coefficient. RISEC, Volume 47 (2000), No.1, 87-94.

Preston, Samuel H. (1975). The changing relation between mortality and level of economic development. Population Studies, V.29, Issue 2 (Jul., 1975), 231-48.

Preston, Samuel H. (1980). Causes and consequences of mortality declines in less developed countries during the twentieth century. In: Richard S. Easterlin (editor): Population and Economic Change in Developing Countries. National Bureau of Economic Research, The University of Chicago Press, Chicago, 1980, 289-341.

Quah, Danny T. (1996). Empirics for economic growth and convergence. European Economic Review, 40(1996), 1353-75.

Rosen, Sherwin (1988). The value of changes in life expectancy. Journal of Risk and Uncertainty, 1: 285-304.

Sala-i-Martin, Xavier (2002). "The world distribution of income (estimated from individual country distributions).” NBER Working Paper w8933, May 2002.

Soares, Rodrigo R. (2003). "Mortality reductions, educational attainment, and fertility choice." Unpublished Manuscript, University of Maryland.

Usher, Dan (1973). An imputation of the measure of economic growth for changes in life expectancy. In: Milton Moss (editor). The Measurement of Economic and Social Performance, Studies in Income and Wealth, Volume 38. Conference on Research in Income and Wealth. New York, National Bureau of Economic Research and Columbia University Press, 1973, 193-225.

Viscusi, W. Kip (1993). The value of risks to life and health. Journal of Economic Literature, V31, Issue 4 (Dec., 1993), 1912-46.

Viscusi, W. Kip and Joseph E. Aldy (2003). "The value of a statistical life: A critical review of market estimates throughout the world." NBER Working Paper w9487, February 2003. 
Table 1: Dispersion Measure for Income per capita and Life Expectancy at Birth

\begin{tabular}{l|cc|cc}
\hline \hline & \multicolumn{2}{|c|}{ Std Dev } & \multicolumn{2}{c}{ Std Dev/Mean } \\
& 65 & 95 & 65 & 95 \\
\hline GDP & 2680.8 & 5410.0 & 0.5518 & 0.5403 \\
$\ln ($ GDP) & 0.6571 & 0.6953 & 0.0791 & 0.0771 \\
life & 5.0435 & 3.1181 & 0.0752 & 0.0422 \\
\hline \hline
\end{tabular}


Table 2: Valuation of Longevity Gains by Countries and Groups of Countries

\begin{tabular}{|c|c|c|c|c|c|c|c|c|c|}
\hline \multirow[t]{2}{*}{ "Country } & \multicolumn{2}{|c|}{ GDP per capita } & \multicolumn{2}{|c|}{ Life Exp at Birth } & \multicolumn{2}{|c|}{ Growth Rates } & \multirow{2}{*}{$\begin{array}{c}\text { Value of } \\
\text { Longevity Gains } \\
\text { in Annual Income } \\
\end{array}$} & \multirow{2}{*}{\begin{tabular}{|c|} 
Growth Rate with \\
Income Equivalent \\
Compensation \\
\end{tabular}} & \multirow{2}{*}{$\begin{array}{c}\text { Total Lifetime } \\
\text { Value of } \\
\text { Longevity Gains }\end{array}$} \\
\hline & 65 & 95 & 65 & 95 & GDP & Life & & & \\
\hline DEVELOPED & 6,855 & 13,853 & 70 & 76 & $111.6 \%$ & $9.0 \%$ & 1,747 & $140.2 \%$ & 50,280 \\
\hline AUSTRALIA & 9,249 & 16,046 & 70 & 77 & $73.5 \%$ & $10.4 \%$ & 2,040 & $95.5 \%$ & 59,219 \\
\hline AUSTRIA & 6,304 & 13,728 & 69 & 76 & $117.8 \%$ & $10.4 \%$ & 2,138 & $151.7 \%$ & 61,209 \\
\hline BELGIUM & 6,932 & 14,285 & 70 & 76 & $106.1 \%$ & $8.8 \%$ & 1,736 & $131.1 \%$ & 50,084 \\
\hline CANADA & 8,464 & 16,779 & 71 & 77 & $98.2 \%$ & $9.4 \%$ & 2,228 & $124.6 \%$ & 64,546 \\
\hline FINLAND & 6,552 & 13,898 & 68 & 75 & $112.1 \%$ & $9.7 \%$ & 1,650 & $137.3 \%$ & 47,603 \\
\hline FRANCE & 7,563 & 14,756 & 71 & 77 & $95.1 \%$ & $9.7 \%$ & 1,718 & $117.8 \%$ & 49,951 \\
\hline GERMANY, FFR & 7,938 & 15,679 & 69 & 75 & $97.5 \%$ & $8.5 \%$ & 2,059 & $123.5 \%$ & 59,235 \\
\hline GREECE & 3,064 & 7,206 & 71 & 77 & $135.2 \%$ & $7.7 \%$ & 901 & $164.6 \%$ & 25,968 \\
\hline ICELAND & 5,856 & 13,525 & 73 & 78 & $131.0 \%$ & $6.6 \%$ & 1,208 & $151.6 \%$ & 35,575 \\
\hline IRELAND & 4,125 & 11,531 & 69 & 75 & $179.5 \%$ & $7.6 \%$ & 1,327 & $211.7 \%$ & 38,269 \\
\hline ITALY & 6,070 & 13,286 & 69 & 77 & $118.9 \%$ & $11.6 \%$ & 2,466 & $159.5 \%$ & 70,204 \\
\hline JAPAN & 5,012 & 15,502 & 69 & 79 & $209.3 \%$ & $14.3 \%$ & 2,868 & $266.5 \%$ & 82,427 \\
\hline LUXEMBOURG & 8,839 & 20,727 & 68 & 76 & $134.5 \%$ & $10.4 \%$ & 3,066 & $169.2 \%$ & 88,024 \\
\hline NETHERLANDS & 7,509 & 14,250 & 73 & 76 & $89.8 \%$ & $5.1 \%$ & 985 & $102.9 \%$ & 29,064 \\
\hline NEW ZEALAND & 8,883 & 11,933 & 70 & 76 & $34.3 \%$ & $8.0 \%$ & 1,148 & $47.3 \%$ & 33,342 \\
\hline NORWAY & 6,773 & 15,640 & 73 & 76 & $130.9 \%$ & $5.0 \%$ & 1,141 & $147.8 \%$ & 33,642 \\
\hline PORTUGAL & 2,567 & 7,798 & 64 & 74 & $203.8 \%$ & $15.1 \%$ & 2,424 & $298.3 \%$ & 64,920 \\
\hline SPAIN & 4,612 & 10,660 & 70 & 77 & $131.1 \%$ & $9.9 \%$ & 1,537 & $164.5 \%$ & 44,159 \\
\hline SWEDEN & 9,582 & 15,545 & 73 & 78 & $62.2 \%$ & $6.4 \%$ & 1,262 & $75.4 \%$ & 37,322 \\
\hline UK, ENGL. \& WALES & 7,658 & 13,634 & 71 & 76 & $78.0 \%$ & $7.9 \%$ & 1,405 & $96.4 \%$ & 40,944 \\
\hline UK, N. IRELAND & 6,126 & 10,907 & 69 & 75 & $78.0 \%$ & $8.6 \%$ & 1,273 & $98.8 \%$ & 36,746 \\
\hline UK, SCOTLAND & 6,356 & 11,316 & 69 & 74 & $78.0 \%$ & $7.8 \%$ & 1,256 & $97.8 \%$ & 36,130 \\
\hline USA & 11,635 & 19,989 & 69 & 75 & $71.8 \%$ & $8.4 \%$ & 2,358 & $92.1 \%$ & 67,859 \\
\hline DEVELOPING & 2,862 & 6,039 & 65 & 72 & $137.3 \%$ & $11.5 \%$ & 1,265 & $191.9 \%$ & 33,625 \\
\hline ARGENTINA & 4,927 & 6,113 & 67 & 72 & $24.1 \%$ & $6.9 \%$ & 684 & $38.0 \%$ & 19,111 \\
\hline BARBADOS & 3,075 & 5,881 & 66 & 73 & $91.3 \%$ & $10.7 \%$ & 1,080 & $126.4 \%$ & 29,721 \\
\hline BELIZE & & 4,127 & 70 & 74 & & $6.2 \%$ & 649 & & 17,906 \\
\hline BULGARIA & & 4,916 & 70 & 70 & & $0.0 \%$ & 156 & & 4,476 \\
\hline CHILE & 3,468 & 5,793 & 57 & 73 & $67.0 \%$ & $27.8 \%$ & 3,207 & $159.5 \%$ & 79,302 \\
\hline COLOMBIA & 1,848 & 3,614 & 58 & 72 & $95.6 \%$ & $23.4 \%$ & 1,481 & $175.8 \%$ & 36,792 \\
\hline COSTA RICA & 2,482 & 3,529 & 65 & 75 & $42.2 \%$ & $14.8 \%$ & 909 & $78.8 \%$ & 24,348 \\
\hline CUBA & & & 69 & 74 & & $7.3 \%$ & & & \\
\hline CZECHOSLOVAKIA, FR & 2,058 & 3,921 & 70 & 71 & $90.6 \%$ & $1.5 \%$ & 132 & $97.0 \%$ & 3,830 \\
\hline ECUADOR & 1,655 & 2,695 & 60 & 71 & $62.8 \%$ & $17.8 \%$ & 1,290 & $140.8 \%$ & 30,548 \\
\hline EGYPT & 958 & 1,932 & 48 & 66 & $101.6 \%$ & $38.1 \%$ & 1,443 & $252.2 \%$ & 29,871 \\
\hline EL SALVADOR & 1,749 & 2,001 & 59 & 70 & $14.4 \%$ & $18.8 \%$ & 608 & $49.2 \%$ & 15,106 \\
\hline HONG KONG & 3,202 & 16,839 & 69 & 78 & $425.9 \%$ & $14.0 \%$ & 3,808 & $544.8 \%$ & 107,974 \\
\hline HUNGARY & 3,487 & 5,357 & 68 & 69 & $53.6 \%$ & $0.6 \%$ & 287 & $61.9 \%$ & 8,127 \\
\hline MALTA & 1,961 & 16,351 & 68 & 75 & $733.8 \%$ & $10.4 \%$ & 2,544 & $863.5 \%$ & 72,840 \\
\hline MAURITIUS & 3,022 & 7,304 & 59 & 69 & $141.7 \%$ & $16.5 \%$ & 2,344 & $219.3 \%$ & 60,772 \\
\hline MEXICO & 3,320 & 5,799 & 59 & 71 & $74.7 \%$ & $20.9 \%$ & 2,256 & $142.6 \%$ & 57,194 \\
\hline PHILIPPINES & 1,281 & 1,788 & 65 & 70 & $39.6 \%$ & $8.2 \%$ & 227 & $57.4 \%$ & 6,127 \\
\hline POLAND & 2,946 & 4,744 & 68 & 71 & $61.0 \%$ & $3.6 \%$ & 412 & $75.0 \%$ & 11,616 \\
\hline PUERTO RICO & 4,158 & 7,468 & 69 & 73 & $79.6 \%$ & $5.7 \%$ & 918 & $101.7 \%$ & 25,761 \\
\hline ROMANIA & 623 & 1,859 & 74 & 69 & $198.3 \%$ & $-6.9 \%$ & 138 & $220.5 \%$ & 3,795 \\
\hline SINGAPORE & 2,160 & 14,823 & 66 & 76 & $586.1 \%$ & $16.2 \%$ & 3,342 & $740.8 \%$ & 94,023 \\
\hline TRINIDAD AND TOBAGO & 5,827 & 8,524 & 65 & 70 & $46.3 \%$ & $7.5 \%$ & 1,104 & $65.2 \%$ & 30,643 \\
\hline URUGUAY & 3,978 & 5,761 & 67 & 72 & $44.8 \%$ & $7.0 \%$ & 688 & $62.1 \%$ & 19,165 \\
\hline VENEZUELA & 5,094 & 5,251 & 65 & 71 & $3.1 \%$ & $9.7 \%$ & 864 & $20.0 \%$ & 23,466 \\
\hline YUGOSLAVIA, FR & 2,550 & 4,593 & 64 & 72 & $80.1 \%$ & $11.4 \%$ & 1,050 & $121.3 \%$ & 28,116 \\
\hline
\end{tabular}


Table 3: Decomposition of Life Expectancy Convergence

\begin{tabular}{l|ccc}
\hline \hline Cause & Coef & R Sq & Contribution \\
\hline Total & $-0.6201^{*}$ & 0.61 & $100.00 \%$ \\
\hline R01: INFECTIOUS & $-0.0491^{*}$ & 0.22 & $7.92 \%$ \\
R02: NEOPLASMS & 0.0097 & 0.01 & $-1.56 \%$ \\
R03: ENDOCRINE, METABOLIC AND BLOOD & -0.0066 & 0.01 & $1.06 \%$ \\
DISEASES, NUTRITIONAL DEFFICIENCIES & 0.0001 & 0.00 & $-0.01 \%$ \\
R04: MENTAL DISORDERS & $0.0733^{*}$ & 0.16 & $-11.83 \%$ \\
R05: NERVOUS SYSTEM AND SENSES ORGANS & $0.0655^{*}$ & 0.03 & $-10.56 \%$ \\
R06: HEART AND CIRCULATORY & $-0.3731^{*}$ & 0.80 & $60.16 \%$ \\
R07: RESPIRATORY AND DIGESTIVE & $0.0129{ }^{*}$ & 0.11 & $-2.08 \%$ \\
R08: URINARY AND GENITAL & $-0.0084^{*}$ & 0.50 & $1.36 \%$ \\
R09: ABORTION AND OBSTETRIC CAUSES & $-0.0036{ }^{*}$ & 0.33 & $0.58 \%$ \\
R10: SKIN AND MUSCULOSKELETAL & $-0.0561{ }^{*}$ & 0.38 & $9.05 \%$ \\
R11: CONGENITAL ANOMALIES AND PERINATAL & $-0.2012^{*}$ & 0.41 & $32.44 \%$ \\
PERIOD CONDITIONS & 0.0209 & 0.07 & $-3.36 \%$ \\
R12: ILL-DEFINED & -0.1044 & & $16.84 \%$ \\
R13: ACCIDENTS, SUICIDES AND HOMICIDES & & &
\end{tabular}




\begin{tabular}{|c|c|c|c|c|c|c|c|c|c|c|c|c|c|c|}
\hline$\overline{\overline{\text { Country }}}$ & Total & $\begin{array}{l}\text { R01: } \\
\text { INFECTIOUS }\end{array}$ & $\begin{array}{l}\text { R02: } \\
\text { NEOPLASMS }\end{array}$ & $\begin{array}{l}\text { R03: } \\
\text { ENDOCRINE, } \\
\text { METABOLIC, } \\
\text { BLOOD, } \\
\text { NUTRITIONAL }\end{array}$ & $\begin{array}{l}\text { R04: } \\
\text { MENTAL } \\
\text { DISORDERS }\end{array}$ & $\begin{array}{l}\text { R05: } \\
\text { NERVOUS } \\
\text { SYSTEM AND } \\
\text { SENSES } \\
\text { ORGANS }\end{array}$ & $\begin{array}{l}\text { R06: } \\
\text { HEART AND } \\
\text { CIRCULATORY }\end{array}$ & $\begin{array}{l}\text { R07 } \\
\text { RESPIRATORY } \\
\text { AND DIGESTIVE }\end{array}$ & $\begin{array}{l}\text { R08: } \\
\text { URINARY AND } \\
\text { GENITAL }\end{array}$ & $\begin{array}{l}\text { R09: } \\
\text { ABORTION } \\
\text { AND } \\
\text { OBSTETRIC } \\
\text { CAUSES }\end{array}$ & $\begin{array}{l}\text { R10: } \\
\text { SKIN AND } \\
\text { MUSCULOSKELETAL }\end{array}$ & $\begin{array}{l}\text { R11: } \\
\text { CONGENITAL } \\
\text { ANOMALIES } \\
\text { AND } \\
\text { PERINATAL } \\
\text { PERIOD } \\
\text { CONDITIONS }\end{array}$ & $\begin{array}{l}\text { R12: } \\
\text { ILL-DEFINED }\end{array}$ & $\begin{array}{l}\text { R13: } \\
\text { ACIDENTS, } \\
\text { SUICIDES AND } \\
\text { HOMICIDES }\end{array}$ \\
\hline DEVELOPED & 1747.49 & 64.43 & 65.32 & 10.67 & -2.39 & 232.99 & 167.98 & 284.40 & 40.47 & 7.03 & 6.20 & 543.79 & 27.34 & 119.46 \\
\hline AUSTRALIA & 2040.31 & 31.04 & 35.57 & 15.69 & -11.12 & 262.38 & 458.96 & 231.81 & 54.74 & 7.36 & 8.09 & 517.15 & -47.67 & 238.73 \\
\hline AUSTRIA & 2138.08 & 72.45 & 132.99 & 17.36 & -2.55 & 244.55 & 64.87 & 342.17 & 43.39 & 8.54 & 11.67 & 760.96 & -2.49 & 202.61 \\
\hline BELGIUM & 1735.96 & 52.56 & 69.69 & 19.31 & 14.13 & 155.00 & 257.99 & 170.42 & 29.63 & 4.03 & 2.99 & 631.89 & 84.91 & 63.04 \\
\hline CANADA & 2227.59 & 36.86 & 54.62 & -5.75 & -0.72 & 215.71 & 445.40 & 276.99 & 34.89 & 8.63 & 9.37 & 722.31 & -69.10 & 293.81 \\
\hline FINLAND & 1649.54 & 65.73 & 132.21 & 27.04 & -3.93 & 235.98 & 247.90 & 136.69 & 60.14 & 5.78 & 3.23 & 436.88 & -12.58 & 102.70 \\
\hline FRANCE & 1717.85 & 84.13 & 46.73 & -23.15 & 20.66 & 244.64 & 110.66 & 214.63 & 28.42 & 5.44 & 4.46 & 499.88 & 143.06 & 113.94 \\
\hline GERMANY, FFR & 2059.01 & 58.65 & 91.70 & 23.14 & -16.20 & 286.25 & 17.80 & 254.07 & 49.55 & 13.44 & 7.42 & 884.02 & -48.05 & 259.01 \\
\hline GREECE & 901.19 & 84.68 & 17.03 & 31.16 & 6.60 & 119.78 & -65.01 & 231.38 & 19.89 & 3.66 & 4.23 & 282.59 & 111.70 & 1.82 \\
\hline ICELAND & 1208.15 & 30.62 & 101.57 & 1.51 & 5.51 & 194.32 & 87.99 & 147.49 & 55.26 & 4.40 & 3.45 & 339.38 & 1.25 & 147.85 \\
\hline IRELAND & 1327.01 & 60.42 & 31.20 & 25.06 & 0.52 & 177.03 & 129.44 & 238.96 & 35.01 & 5.98 & 6.09 & 529.41 & 0.72 & -14.90 \\
\hline ITALY & 2465.99 & 129.49 & 47.16 & -4.37 & -8.24 & 242.71 & 175.47 & 609.35 & 39.81 & 12.35 & 8.18 & 802.71 & 24.40 & 102.15 \\
\hline JAPAN & 2867.69 & 186.91 & 105.77 & 54.69 & 14.39 & 562.29 & 13.00 & 463.16 & 53.96 & 14.41 & 14.56 & 521.31 & $\begin{array}{l}236.57 \\
136.57\end{array}$ & 289.87 \\
\hline LUXEMBOURG & 3065.75 & 81.99 & 190.35 & 61.10 & 13.97 & 274.77 & 353.75 & 201.92 & 84.02 & 12.43 & 6.37 & 1097.79 & 214.84 & 134.40 \\
\hline NETHERLANDS & 984.60 & 8.78 & 72.13 & -6.37 & 1.53 & 189.26 & 67.43 & 80.13 & 32.83 & 4.90 & 6.89 & 325.60 & -4.95 & 145.52 \\
\hline NEW ZEALAND & 1147.93 & 32.90 & 17.94 & 15.41 & 8.50 & 180.29 & 217.45 & 220.23 & 26.91 & 5.46 & 6.36 & 339.14 & -61.62 & 27.54 \\
\hline NORWAY & 1140.88 & 21.69 & 39.96 & 17.05 & -38.10 & 244.42 & 55.76 & 115.62 & 40.52 & 3.93 & 4.05 & 397.07 & 66.93 & 111.46 \\
\hline PORTUGAL & 2424.24 & 173.17 & -5.03 & 0.94 & 3.00 & 210.38 & -5.92 & 1099.26 & 41.63 & 8.73 & 4.81 & 501.57 & 73.48 & 11.10 \\
\hline SPAIN & 1536.73 & 140.56 & -13.08 & -16.64 & 3.65 & 259.30 & 67.76 & 464.68 & 32.16 & 6.76 & 6.22 & 298.51 & 130.67 & -3.90 \\
\hline SWEDEN & 1262.24 & 19.15 & 89.08 & 23.57 & -19.56 & 184.75 & 130.60 & 118.03 & 45.99 & 2.56 & 3.86 & 428.92 & -32.80 & 158.70 \\
\hline UK, ENGL. \& WALES & 1405.20 & 20.32 & 79.80 & 14.18 & -11.11 & 200.29 & 162.53 & 246.80 & 31.02 & 4.40 & 4.07 & 441.58 & -31.02 & 111.43 \\
\hline UK, N. IRELAND & 1272.60 & 32.57 & 30.39 & 20.78 & 1.51 & 183.13 & 190.45 & 192.43 & 24.48 & 5.21 & 5.53 & 481.41 & -7.24 & -4.14 \\
\hline UK, SCOTLAND & 1255.63 & 27.83 & 58.43 & 12.13 & -29.47 & 204.43 & 141.50 & 179.07 & 27.46 & 3.97 & 4.26 & 456.59 & -19.29 & 86.82 \\
\hline USA & 2357.99 & 29.45 & 76.22 & -78.34 & -7.88 & 287.05 & 537.84 & 305.89 & 39.00 & 9.32 & 6.38 & 810.48 & -22.81 & 168.04 \\
\hline DEVELOPING & 1264.82 & 107.29 & 7.38 & 10.01 & -0.53 & 94.62 & -9.99 & 397.81 & 10.26 & 8.97 & 3.27 & 260.84 & 203.55 & 9.34 \\
\hline ARGENTINA & 684.49 & 60.00 & 31.34 & -12.07 & 2.84 & 113.00 & -41.32 & 236.99 & 7.72 & 5.31 & 2.53 & 117.74 & 104.24 & 9.41 \\
\hline BARBADOS & 1079.87 & 74.21 & 7.34 & -33.24 & 2.80 & 134.51 & 28.74 & 303.13 & 16.47 & 18.18 & 1.12 & 399.36 & 42.11 & $\begin{array}{l}-16.54 \\
-16.54\end{array}$ \\
\hline BELIZE & 649.41 & 13.97 & 5.73 & 13.12 & -1.37 & 47.52 & -43.91 & 316.40 & -1.71 & 2.38 & -1.01 & 87.55 & 235.42 & -62.82 \\
\hline BULGARIA & 155.65 & 16.66 & -0.52 & -1.08 & -1.79 & 90.16 & -149.97 & 149.29 & 9.10 & 1.48 & 1.38 & 81.31 & -1.85 & -5.66 \\
\hline CHILE & 3206.87 & 254.62 & 35.94 & 20.62 & 8.78 & 133.77 & 51.53 & 1143.64 & 17.81 & 26.01 & 8.22 & 578.81 & 142.37 & 65.66 \\
\hline COLOMBIA & 1481.11 & 174.15 & 9.43 & 67.08 & 2.43 & 57.57 & -1.96 & 527.90 & 13.84 & 14.49 & 6.34 & 185.00 & 210.52 & -53.71 \\
\hline COSTA RICA & 909.07 & 117.51 & 25.99 & 21.77 & 2.73 & 36.44 & 3.73 & 325.21 & 8.53 & 10.49 & 3.20 & 101.96 & 126.19 & 8.70 \\
\hline CZECHOSLOVAKIA, FR & 132.49 & 18.28 & -7.55 & 6.91 & -0.53 & 39.26 & -45.05 & 35.15 & 2.88 & 0.95 & 1.74 & 63.61 & -0.47 & 19.21 \\
\hline ECUADOR & 1289.69 & 200.12 & -6.15 & 12.17 & -2.05 & 24.32 & -22.14 & 449.69 & 2.49 & 10.84 & 5.09 & 79.30 & 256.74 & -2.52 \\
\hline EGYPT & 1443.14 & -13.64 & 1.28 & 10.01 & -0.07 & 2.00 & -43.70 & 969.52 & $\begin{array}{l}2.49 \\
2.28\end{array}$ & $\begin{array}{l}2.04 \\
2.42\end{array}$ & $\begin{array}{l}.03 \\
2.37\end{array}$ & 187.57 & 70.32 & 17.48 \\
\hline EL SALVADOR & 607.60 & 64.99 & -4.31 & 11.90 & -9.25 & 11.88 & -25.48 & 192.64 & -3.21 & 4.23 & 3.12 & 84.21 & 209.18 & -12.04 \\
\hline HONG KONG & 3807.78 & 587.74 & 49.54 & 36.22 & 3.45 & 320.06 & 103.20 & 886.17 & 39.83 & 10.97 & 5.67 & 750.69 & 353.25 & 196.13 \\
\hline HUNGARY & 287.08 & 35.09 & -42.71 & 3.61 & -9.32 & 91.42 & -90.55 & 49.33 & 8.86 & 1.96 & 4.80 & 256.77 & 2.89 & -25.22 \\
\hline MALTA & 2544.21 & 59.52 & -29.69 & 60.18 & 4.99 & 267.59 & 267.35 & 338.73 & 25.42 & 9.91 & 14.04 & 779.65 & 468.74 & 20.08 \\
\hline MAURITIUS & 2343.90 & 95.71 & -4.30 & 188.26 & -12.23 & 131.89 & -79.39 & 873.64 & -11.46 & 18.94 & 7.19 & 287.06 & 553.21 & -3.81 \\
\hline MEXICO & 2255.92 & 203.54 & -7.02 & -12.35 & 1.12 & 51.43 & -3.07 & 971.56 & 4.33 & 21.34 & 2.88 & 296.40 & 353.63 & 31.51 \\
\hline PHILIPPINES & 227.17 & 43.85 & $\begin{array}{r}-7.02 \\
-4.90\end{array}$ & 23.88 & $\begin{array}{l}-0.25 \\
-0.25\end{array}$ & $\begin{array}{l}11.18 \\
11.18\end{array}$ & $\begin{array}{l}-22.56 \\
-22\end{array}$ & 110.78 & 2.30 & 2.64 & $\begin{array}{l}2.00 \\
1.00\end{array}$ & 21.29 & 31.01 & $\begin{array}{l}-2.95 \\
-2105\end{array}$ \\
\hline POLAND & 411.93 & 62.59 & -15.57 & 9.68 & -4.16 & 51.93 & -51.65 & 177.61 & 5.78 & 1.27 & 5.21 & 123.52 & 45.73 & -10.70 \\
\hline PUERTO RICO & 918.01 & 97.70 & 35.07 & $\begin{array}{l}3.00 \\
-115.27\end{array}$ & -11.79 & 92.9 & 7.92 & 278.22 & 5.88 & 6.62 & 0.07 & 320.43 & 164.14 & -15.08 \\
\hline ROMANIA & 137.89 & 19.97 & 0.14 & -1.00 & -2.03 & 29.70 & -31.21 & 75.15 & 2.72 & 0.78 & 0.90 & 40.78 & 2.83 & 3.50 \\
\hline SINGAPORE & 3341.93 & 256.35 & 89.27 & 60.72 & 4.91 & 234.45 & 36.11 & 543.20 & 47.42 & 11.86 & -1.52 & 627.22 & 814.04 & 133.09 \\
\hline TRINIDAD AND TOBAGO & 1103.73 & 51.29 & $\begin{array}{l}0.27 \\
1.85\end{array}$ & -115.28 & 0.58 & $\begin{array}{l}194.401 \\
194.01\end{array}$ & 20.43 & $\begin{array}{l}3408.92 \\
368.92\end{array}$ & $\begin{array}{l}41.42 \\
17.07\end{array}$ & 21.40 & 1.33 & 412.78 & 72.34 & -32.91 \\
\hline URUGUAY & 687.77 & 46.93 & 16.23 & 6.69 & 7.76 & 99.09 & -17.60 & 145.11 & 9.47 & 5.50 & 3.56 & 293.32 & 49.24 & -23.46 \\
\hline VENEZUELA & 863.97 & 33.98 & 14.31 & -8.14 & 0.38 & 47.35 & -43.29 & 211.92 & $\begin{array}{l}13.41 \\
13.53\end{array}$ & 8.84 & -0.18 & 61.72 & $\begin{array}{l}494.09 \\
494\end{array}$ & -11.83 \\
\hline YUGOSLAVIA, FR & 1049.71 & 107.15 & -16.18 & -4.15 & -1.29 & 52.13 & -55.86 & 265.42 & 9.14 & 5.43 & 2.64 & 283.00 & 288.77 & 8.11 \\
\hline
\end{tabular}




\begin{tabular}{|c|c|c|c|c|c|c|c|c|c|c|c|c|c|c|}
\hline$\overline{\overline{\text { Country }}}$ & Sum & $\begin{array}{l}\text { R01: } \\
\text { INFECTIOUS }\end{array}$ & $\begin{array}{l}\text { R02: } \\
\text { NEOPLASMS }\end{array}$ & $\begin{array}{l}\text { R03: } \\
\text { ENDOCRINE, } \\
\text { METABOLIC, } \\
\text { BLOOD, } \\
\text { NUTRITIONAL }\end{array}$ & $\begin{array}{l}\text { R04: } \\
\text { MENTAL } \\
\text { DISORDERS } \\
\end{array}$ & $\begin{array}{l}\text { R05: } \\
\text { NERVOUS } \\
\text { SYSTEM AND } \\
\text { SENSES } \\
\text { ORGANS }\end{array}$ & $\begin{array}{l}\text { R06: } \\
\text { HEART AND } \\
\text { CIRCULATORY }\end{array}$ & $\begin{array}{l}\text { R07: } \\
\text { RESPIRATORY } \\
\text { AND DIGESTIVE }\end{array}$ & $\begin{array}{l}\text { R08: } \\
\text { URINARY AND } \\
\text { GENITAL }\end{array}$ & $\begin{array}{l}\text { R09: } \\
\text { ABORTION } \\
\text { AND } \\
\text { OBSTETRIC } \\
\text { CAUSES }\end{array}$ & $\begin{array}{l}\text { R10: } \\
\text { SKIN AND } \\
\text { MUSCULOSKELETAL }\end{array}$ & $\begin{array}{l}\text { R11: } \\
\text { CONGENITAL } \\
\text { ANOMALIES } \\
\text { AND } \\
\text { PERINATAL } \\
\text { PERIOD } \\
\text { CONDITIONS }\end{array}$ & $\begin{array}{l}\text { R12: } \\
\text { ILL-DEFINED }\end{array}$ & $\begin{array}{l}\text { R13: } \\
\text { ACCIDENTS, } \\
\text { SUICIIES AND } \\
\text { HOMICIDES }\end{array}$ \\
\hline DEVELOPED & $90.29 \%$ & $4.03 \%$ & $4.25 \%$ & $0.78 \%$ & $-0.22 \%$ & $15.40 \%$ & $10.49 \%$ & $17.80 \%$ & $2.69 \%$ & $0.44 \%$ & $0.41 \%$ & $34.87 \%$ & $1.63 \%$ & $7.44 \%$ \\
\hline AUSTRALIA & $88.36 \%$ & $1.72 \%$ & $1.97 \%$ & $0.87 \%$ & $-0.62 \%$ & $14.55 \%$ & $25.46 \%$ & $12.86 \%$ & $3.04 \%$ & $0.41 \%$ & $0.45 \%$ & $28.69 \%$ & $-2.64 \%$ & $13.24 \%$ \\
\hline AUSTRIA & $88.70 \%$ & $3.82 \%$ & $7.01 \%$ & $0.92 \%$ & $-0.13 \%$ & $12.89 \%$ & $3.42 \%$ & $18.04 \%$ & $2.29 \%$ & $0.45 \%$ & $0.62 \%$ & $40.12 \%$ & $-0.13 \%$ & $10.68 \%$ \\
\hline BELGIUM & $89.61 \%$ & $3.38 \%$ & $4.48 \%$ & $1.24 \%$ & $0.91 \%$ & $9.96 \%$ & $16.58 \%$ & $10.96 \%$ & $1.90 \%$ & $0.26 \%$ & $0.19 \%$ & $40.62 \%$ & $5.46 \%$ & $4.05 \%$ \\
\hline CANADA & $90.82 \%$ & $1.82 \%$ & $2.70 \%$ & $-0.28 \%$ & $-0.04 \%$ & $10.66 \%$ & $22.02 \%$ & $13.69 \%$ & $1.72 \%$ & $0.43 \%$ & $0.46 \%$ & $35.70 \%$ & $-3.42 \%$ & $14.52 \%$ \\
\hline FINLAND & $87.16 \%$ & $4.57 \%$ & $9.20 \%$ & $1.88 \%$ & $-0.27 \%$ & $16.41 \%$ & $17.24 \%$ & $9.51 \%$ & $4.18 \%$ & $0.40 \%$ & $0.22 \%$ & $30.39 \%$ & $-0.87 \%$ & $7.14 \%$ \\
\hline FRANCE & $86.94 \%$ & $5.63 \%$ & $3.13 \%$ & $-1.55 \%$ & $1.38 \%$ & $16.38 \%$ & $7.41 \%$ & $14.37 \%$ & $1.90 \%$ & $0.36 \%$ & $0.30 \%$ & $33.47 \%$ & $9.58 \%$ & $7.63 \%$ \\
\hline GERMANY, FFR & $91.35 \%$ & $3.12 \%$ & $4.88 \%$ & $1.23 \%$ & $-0.86 \%$ & $15.22 \%$ & $0.95 \%$ & $13.51 \%$ & $2.63 \%$ & $0.71 \%$ & $0.39 \%$ & $47.00 \%$ & $-2.55 \%$ & $13.77 \%$ \\
\hline GREECE & $94.27 \%$ & $9.97 \%$ & $2.00 \%$ & $3.67 \%$ & $0.78 \%$ & $14.10 \%$ & $-7.65 \%$ & $27.24 \%$ & $2.34 \%$ & $0.43 \%$ & $0.50 \%$ & $33.27 \%$ & $13.15 \%$ & $0.21 \%$ \\
\hline ICELAND & $92.75 \%$ & $2.73 \%$ & $9.06 \%$ & $0.13 \%$ & $0.49 \%$ & $17.34 \%$ & $7.85 \%$ & $13.16 \%$ & $4.93 \%$ & $0.39 \%$ & $0.31 \%$ & $30.29 \%$ & $0.11 \%$ & $13.19 \%$ \\
\hline IRELAND & $92.31 \%$ & $4.93 \%$ & $2.55 \%$ & $2.05 \%$ & $0.04 \%$ & $14.45 \%$ & $10.57 \%$ & $19.51 \%$ & $2.86 \%$ & $0.49 \%$ & $0.50 \%$ & $43.22 \%$ & $0.06 \%$ & $-1.22 \%$ \\
\hline ITALY & $88.45 \%$ & $5.94 \%$ & $2.16 \%$ & $-0.20 \%$ & $-0.38 \%$ & $11.13 \%$ & $8.04 \%$ & $27.94 \%$ & $1.83 \%$ & $0.57 \%$ & $0.37 \%$ & $36.80 \%$ & $1.12 \%$ & $4.68 \%$ \\
\hline JAPAN & $84.77 \%$ & $7.69 \%$ & $4.35 \%$ & $2.25 \%$ & $0.59 \%$ & $23.13 \%$ & $0.53 \%$ & $19.05 \%$ & $2.22 \%$ & $0.59 \%$ & $0.60 \%$ & $21.45 \%$ & $5.62 \%$ & $11.92 \%$ \\
\hline LUXEMBOURG & $88.97 \%$ & $3.01 \%$ & $6.98 \%$ & $2.24 \%$ & $0.51 \%$ & $10.07 \%$ & $12.97 \%$ & $7.40 \%$ & $3.08 \%$ & $0.46 \%$ & $0.23 \%$ & $40.25 \%$ & $7.88 \%$ & $4.93 \%$ \\
\hline NETHERLANDS & $93.81 \%$ & $0.95 \%$ & $7.81 \%$ & $-0.69 \%$ & $0.17 \%$ & $20.49 \%$ & $7.30 \%$ & $8.67 \%$ & $3.55 \%$ & $0.53 \%$ & $0.75 \%$ & $35.25 \%$ & $-0.54 \%$ & $15.75 \%$ \\
\hline NEW ZEALAND & $90.29 \%$ & $3.17 \%$ & $1.73 \%$ & $1.49 \%$ & $0.82 \%$ & $17.39 \%$ & $20.98 \%$ & $21.25 \%$ & $2.60 \%$ & $0.53 \%$ & $0.61 \%$ & $32.72 \%$ & $-5.94 \%$ & $2.66 \%$ \\
\hline NORWAY & $94.70 \%$ & $2.01 \%$ & $3.70 \%$ & $1.58 \%$ & $-3.53 \%$ & $22.62 \%$ & $5.16 \%$ & $10.70 \%$ & $3.75 \%$ & $0.36 \%$ & $0.37 \%$ & $36.75 \%$ & $6.20 \%$ & $10.32 \%$ \\
\hline PORTUGAL & $87.33 \%$ & $8.18 \%$ & $-0.24 \%$ & $0.04 \%$ & $0.14 \%$ & $9.94 \%$ & $-0.28 \%$ & $51.92 \%$ & $1.97 \%$ & $0.41 \%$ & $0.23 \%$ & $23.69 \%$ & $3.47 \%$ & $0.52 \%$ \\
\hline SPAIN & $89.58 \%$ & $10.21 \%$ & $-0.95 \%$ & $-1.21 \%$ & $0.27 \%$ & $18.84 \%$ & $4.92 \%$ & $33.75 \%$ & $2.34 \%$ & $0.49 \%$ & $0.45 \%$ & $21.68 \%$ & $9.49 \%$ & $-0.28 \%$ \\
\hline SWEDEN & $91.33 \%$ & $1.66 \%$ & $7.73 \%$ & $2.04 \%$ & $-1.70 \%$ & $16.03 \%$ & $11.33 \%$ & $10.24 \%$ & $3.99 \%$ & $0.22 \%$ & $0.33 \%$ & $37.21 \%$ & $-2.84 \%$ & $13.77 \%$ \\
\hline UK, ENGL. \& WALES & $90.69 \%$ & $1.59 \%$ & $6.26 \%$ & $1.11 \%$ & $-0.87 \%$ & $15.72 \%$ & $12.75 \%$ & $19.37 \%$ & $2.43 \%$ & $0.35 \%$ & $0.32 \%$ & $34.65 \%$ & $-2.43 \%$ & $8.74 \%$ \\
\hline UK, N. IRELAND & $90.88 \%$ & $2.82 \%$ & $2.63 \%$ & $1.80 \%$ & $0.13 \%$ & $15.83 \%$ & $16.47 \%$ & $16.64 \%$ & $2.12 \%$ & $0.45 \%$ & $0.48 \%$ & $41.63 \%$ & $-0.63 \%$ & $-0.36 \%$ \\
\hline UK, SCOTLAND & $91.89 \%$ & $2.41 \%$ & $5.06 \%$ & $1.05 \%$ & $-2.55 \%$ & $17.72 \%$ & $12.26 \%$ & $15.52 \%$ & $2.38 \%$ & $0.34 \%$ & $0.37 \%$ & $39.57 \%$ & $-1.67 \%$ & $7.53 \%$ \\
\hline USA & $91.63 \%$ & $1.36 \%$ & $3.53 \%$ & $-3.63 \%$ & $-0.36 \%$ & $13.29 \%$ & $24.89 \%$ & $14.16 \%$ & $1.81 \%$ & $0.43 \%$ & $0.30 \%$ & $37.51 \%$ & $-1.06 \%$ & $7.78 \%$ \\
\hline DEVELOPING & $91.68 \%$ & $10.31 \%$ & $-0.26 \%$ & $0.72 \%$ & $-0.32 \%$ & $12.07 \%$ & $-8.31 \%$ & $39.25 \%$ & $1.20 \%$ & $0.86 \%$ & $0.45 \%$ & $27.30 \%$ & $17.04 \%$ & $-0.31 \%$ \\
\hline ARGENTINA & $93.17 \%$ & $9.41 \%$ & $4.91 \%$ & $-1.89 \%$ & $0.45 \%$ & $17.72 \%$ & $-6.48 \%$ & $37.16 \%$ & $1.21 \%$ & $0.83 \%$ & $0.40 \%$ & $18.46 \%$ & $16.35 \%$ & $1.48 \%$ \\
\hline BARBADOS & $90.58 \%$ & $7.59 \%$ & $0.75 \%$ & $-3.40 \%$ & $0.29 \%$ & $13.75 \%$ & $2.94 \%$ & $30.99 \%$ & $1.68 \%$ & $1.86 \%$ & $0.11 \%$ & $40.83 \%$ & $4.31 \%$ & $-1.69 \%$ \\
\hline BELIZE & $94.13 \%$ & $2.28 \%$ & $0.94 \%$ & $2.15 \%$ & $-0.22 \%$ & $7.77 \%$ & $-7.18 \%$ & $51.76 \%$ & $-0.28 \%$ & $0.39 \%$ & $-0.17 \%$ & $14.32 \%$ & $38.51 \%$ & $-10.28 \%$ \\
\hline BULGARIA & $121.11 \%$ & $8.84 \%$ & $-0.28 \%$ & $-0.57 \%$ & $-0.95 \%$ & $47.83 \%$ & $-79.56 \%$ & $79.20 \%$ & $4.83 \%$ & $0.79 \%$ & $0.73 \%$ & $43.14 \%$ & $-0.98 \%$ & $-3.00 \%$ \\
\hline CHILE & $77.58 \%$ & $10.23 \%$ & $1.44 \%$ & $0.83 \%$ & $0.35 \%$ & $5.38 \%$ & $2.07 \%$ & $45.97 \%$ & $0.72 \%$ & $1.05 \%$ & $0.33 \%$ & $23.27 \%$ & $5.72 \%$ & $2.64 \%$ \\
\hline COLOMBIA & $81.90 \%$ & $14.36 \%$ & $0.78 \%$ & $5.53 \%$ & $0.20 \%$ & $4.75 \%$ & $-0.16 \%$ & $43.52 \%$ & $1.14 \%$ & $1.19 \%$ & $0.52 \%$ & $15.25 \%$ & $17.35 \%$ & $-4.43 \%$ \\
\hline COSTA RICA & $87.17 \%$ & $14.83 \%$ & $3.28 \%$ & $2.75 \%$ & $0.34 \%$ & $4.60 \%$ & $0.47 \%$ & $41.04 \%$ & $1.08 \%$ & $1.32 \%$ & $0.40 \%$ & $12.87 \%$ & $15.92 \%$ & $1.10 \%$ \\
\hline CZECHOSLOVAKIA, FR & $101.46 \%$ & $13.60 \%$ & $-5.61 \%$ & $5.14 \%$ & $-0.39 \%$ & $29.21 \%$ & $-33.51 \%$ & $26.15 \%$ & $2.14 \%$ & $0.71 \%$ & $1.30 \%$ & $47.32 \%$ & $-0.35 \%$ & $14.29 \%$ \\
\hline ECUADOR & $78.15 \%$ & $19.85 \%$ & $-0.61 \%$ & $1.21 \%$ & $-0.20 \%$ & $2.41 \%$ & $-2.20 \%$ & $44.62 \%$ & $0.25 \%$ & $1.08 \%$ & $0.50 \%$ & $7.87 \%$ & $25.47 \%$ & $-0.25 \%$ \\
\hline EGYPT & $83.70 \%$ & $-1.13 \%$ & $0.11 \%$ & $0.83 \%$ & $-0.01 \%$ & $0.17 \%$ & $-3.62 \%$ & $80.27 \%$ & $0.19 \%$ & $0.20 \%$ & $0.20 \%$ & $15.53 \%$ & $5.82 \%$ & $1.45 \%$ \\
\hline EL SALVADOR & $86.87 \%$ & $12.31 \%$ & $-0.82 \%$ & $2.25 \%$ & $-1.75 \%$ & $2.25 \%$ & $-4.83 \%$ & $36.50 \%$ & $-0.61 \%$ & $0.80 \%$ & $0.59 \%$ & $15.95 \%$ & $39.63 \%$ & $-2.28 \%$ \\
\hline HONG KONG & $87.79 \%$ & $17.58 \%$ & $1.48 \%$ & $1.08 \%$ & $0.10 \%$ & $9.57 \%$ & $3.09 \%$ & $26.51 \%$ & $1.19 \%$ & $0.33 \%$ & $0.17 \%$ & $22.46 \%$ & $10.57 \%$ & $5.87 \%$ \\
\hline HUNGARY & $99.96 \%$ & $12.23 \%$ & $-14.88 \%$ & $1.26 \%$ & $-3.25 \%$ & $31.86 \%$ & $-31.56 \%$ & $17.19 \%$ & $3.09 \%$ & $0.68 \%$ & $1.67 \%$ & $89.48 \%$ & $1.01 \%$ & $-8.79 \%$ \\
\hline MALTA & $89.87 \%$ & $2.60 \%$ & $-1.30 \%$ & $2.63 \%$ & $0.22 \%$ & $11.70 \%$ & $11.69 \%$ & $14.81 \%$ & $1.11 \%$ & $0.43 \%$ & $0.61 \%$ & $34.10 \%$ & $20.50 \%$ & $0.88 \%$ \\
\hline MAURITIUS & $87.23 \%$ & $4.68 \%$ & $-0.21 \%$ & $9.21 \%$ & $-0.60 \%$ & $6.45 \%$ & $-3.88 \%$ & $42.73 \%$ & $-0.56 \%$ & $0.93 \%$ & $0.35 \%$ & $14.04 \%$ & $27.06 \%$ & $-0.19 \%$ \\
\hline MEXICO & $84.90 \%$ & $10.63 \%$ & $-0.37 \%$ & $-0.64 \%$ & $0.06 \%$ & $2.69 \%$ & $-0.16 \%$ & $50.73 \%$ & $0.23 \%$ & $1.11 \%$ & $0.15 \%$ & $15.48 \%$ & $18.46 \%$ & $1.65 \%$ \\
\hline PHILIPPINES & $95.64 \%$ & $20.18 \%$ & $-2.26 \%$ & $10.99 \%$ & $-0.12 \%$ & $5.15 \%$ & $-10.38 \%$ & $50.99 \%$ & $1.06 \%$ & $1.22 \%$ & $0.46 \%$ & $9.80 \%$ & $14.27 \%$ & $-1.36 \%$ \\
\hline POLAND & $97.40 \%$ & $15.60 \%$ & $-3.88 \%$ & $2.41 \%$ & $-1.04 \%$ & $12.94 \%$ & $-12.87 \%$ & $44.27 \%$ & $1.44 \%$ & $0.32 \%$ & $1.30 \%$ & $30.78 \%$ & $11.40 \%$ & $-2.67 \%$ \\
\hline PUERTO RICO & $94.43 \%$ & $11.27 \%$ & $4.05 \%$ & $-13.30 \%$ & $-1.36 \%$ & $10.72 \%$ & $0.91 \%$ & $32.09 \%$ & $0.68 \%$ & $0.76 \%$ & $0.01 \%$ & $36.96 \%$ & $18.93 \%$ & $-1.74 \%$ \\
\hline ROMANIA & $103.14 \%$ & $14.04 \%$ & $0.10 \%$ & $-0.70 \%$ & $-1.43 \%$ & $20.89 \%$ & $-21.94 \%$ & $52.84 \%$ & $1.91 \%$ & $0.55 \%$ & $0.63 \%$ & $28.68 \%$ & $1.99 \%$ & $2.46 \%$ \\
\hline SINGAPORE & $85.49 \%$ & $8.97 \%$ & $3.12 \%$ & $2.13 \%$ & $0.17 \%$ & $8.21 \%$ & $1.26 \%$ & $19.01 \%$ & $1.66 \%$ & $0.41 \%$ & $-0.05 \%$ & $21.95 \%$ & $28.49 \%$ & $4.66 \%$ \\
\hline TRINIDAD AND TOBAGO & $91.85 \%$ & $5.06 \%$ & $0.18 \%$ & $-11.37 \%$ & $0.06 \%$ & $19.14 \%$ & $2.02 \%$ & $36.39 \%$ & $1.68 \%$ & $2.11 \%$ & $0.13 \%$ & $40.72 \%$ & $7.14 \%$ & $-3.25 \%$ \\
\hline URUGUAY & $93.32 \%$ & $7.31 \%$ & $2.53 \%$ & $1.04 \%$ & $1.21 \%$ & $15.44 \%$ & $-2.74 \%$ & $22.61 \%$ & $1.48 \%$ & $0.86 \%$ & $0.55 \%$ & $45.70 \%$ & $7.67 \%$ & $-3.66 \%$ \\
\hline VENEZUELA & $95.22 \%$ & $4.13 \%$ & $1.74 \%$ & $-0.99 \%$ & $0.05 \%$ & $5.76 \%$ & $-5.26 \%$ & $25.76 \%$ & $1.64 \%$ & $1.07 \%$ & $-0.02 \%$ & $7.50 \%$ & $60.06 \%$ & $-1.44 \%$ \\
\hline YUGOSLAVIA, FR & $89.96 \%$ & $11.35 \%$ & $-1.71 \%$ & $-0.44 \%$ & $-0.14 \%$ & $5.52 \%$ & $-5.92 \%$ & $28.11 \%$ & $0.97 \%$ & $0.58 \%$ & $0.28 \%$ & $29.97 \%$ & $30.58 \%$ & $0.86 \%$ \\
\hline
\end{tabular}


Table A.1: Classification of ICD Codes into Cause of Death Groups

\begin{tabular}{|c|c|c|c|}
\hline Disease Group & ICD-6/7 A & ICD-6/7 B & ICD-9 \\
\hline R01: INFECTIOUS DISEASES & $\begin{array}{l}\text { A001, A002, A003, A004, A005, } \\
\text { A006, A007, A008, A009, A010, } \\
\text { A011, A012, A013, A014, A015, } \\
\text { A016, A017, A018, A019, A020, } \\
\text { A021, A022, A023, A024, A025, } \\
\text { A026, A027, A028, A029, A030, } \\
\text { A031, A032, A033, A034, A035, } \\
\text { A036, A037, A038, A039, A040, } \\
\text { A041, A042, A043 }\end{array}$ & $\begin{array}{l}\text { B001, B002, } \\
\text { B003, B004, } \\
\text { B005, B006, } \\
\text { B007, B008, } \\
\text { B009, B010, } \\
\text { B011, B012, } \\
\text { B013, B014, } \\
\text { B015, B016, } \\
\text { B017 }\end{array}$ & $\begin{array}{l}\text { B01, B02, B03, B04, } \\
\text { B05, B06, B07 }\end{array}$ \\
\hline R02: NEOPLASMS & $\begin{array}{l}\text { A044, A045, A046, A047, A048, } \\
\text { A049, A050, A051, A052, A053, } \\
\text { A054, A055, A056, A057, A058, } \\
\text { A059, A060 }\end{array}$ & B018, B019 & $\begin{array}{l}\text { B08, B09, B10, B11, } \\
\text { B12, B13, B14, B15, } \\
\text { B16, B17 }\end{array}$ \\
\hline $\begin{array}{l}\text { R03: ENDOCRINE, METABOLIC AND } \\
\text { BLOOD DISEASES, NUTRITIONAL } \\
\text { DEFICIENCIES }\end{array}$ & $\begin{array}{l}\text { A061, A062, A063, A064, A065, } \\
\text { A066 }\end{array}$ & B020, B021 & $\mathrm{B} 18, \mathrm{~B} 19, \mathrm{~B} 20$ \\
\hline R04: MENTAL DISORDERS & A067, A068, A069 & & B21 \\
\hline $\begin{array}{l}\text { R05: DISEASES OF THE NERVOUS } \\
\text { SYSTEM AND SENSES ORGANS }\end{array}$ & $\begin{array}{l}\text { A070, A071, A072, A073, A074, } \\
\text { A075, A076, A077, A078 }\end{array}$ & B022, B023 & B22, B23, B24 \\
\hline $\begin{array}{l}\text { R06: HEART AND CIRCULATORY } \\
\text { DISEASES }\end{array}$ & $\begin{array}{l}\text { A079, A080, A081, A082, A083, } \\
\text { A084, A085, A086 }\end{array}$ & $\begin{array}{l}\text { B024, B025, } \\
\text { B026, B027, } \\
\text { B028, B029 }\end{array}$ & $\begin{array}{l}\text { B25, B26, B27, B28, } \\
\text { B29, B30 }\end{array}$ \\
\hline $\begin{array}{l}\text { R07: RESPIRATORY AND DIGESTIVE } \\
\text { DISEASES }\end{array}$ & $\begin{array}{l}\text { A087, A088, A089, A090, A091, } \\
\text { A092, A093, A094, A095, A096, } \\
\text { A097, A098, A099, A100, A101, } \\
\text { A102, A103, A104, A105, A106, } \\
\text { A107 }\end{array}$ & $\begin{array}{l}\text { B030, B031, } \\
\text { B032, B033, } \\
\text { B034, B035, } \\
\text { B036, B037 }\end{array}$ & B31, B32, B33, B34 \\
\hline $\begin{array}{l}\text { R08: URINARY AND GENITAL } \\
\text { DISEASES }\end{array}$ & $\begin{array}{l}\text { A108, A109, A110, A111, A112, } \\
\text { A113, A114 }\end{array}$ & B038, B039 & B35, B36, B37 \\
\hline $\begin{array}{l}\text { R09: ABORTION AND OBSTETRIC } \\
\text { CAUSES }\end{array}$ & $\begin{array}{l}\text { A115, A116, A117, A118, A119, } \\
\text { A120 }\end{array}$ & B040 & B38, B39, B40, B41 \\
\hline $\begin{array}{l}\text { R10: SKIN AND } \\
\text { MUSCULOSKELETAL DISEASES }\end{array}$ & $\begin{array}{l}\text { A121, A122, A123, A124, A125, } \\
\text { A126 }\end{array}$ & & B42, B43 \\
\hline $\begin{array}{l}\text { R11: CONGENITAL ANOMALIES } \\
\text { AND PERINATAL PERIOD } \\
\text { CONDITIONS }\end{array}$ & $\begin{array}{l}\text { A127, A128, A129, A130, A131, } \\
\text { A132, A133, A134, A135 }\end{array}$ & $\begin{array}{l}\text { B041, B042, } \\
\text { B043, B044 }\end{array}$ & B44, B45 \\
\hline R12: ILL-DEFINED & A136, A137 & B045, B046 & B46 \\
\hline $\begin{array}{l}\text { R13: ACCIDENTS, SUICIDES AND } \\
\text { HOMICIDES }\end{array}$ & $\begin{array}{l}\text { A138, A139, A140, A141, A142, } \\
\text { A143, A144, A145, A146, A147, } \\
\text { A148, A149, A150 }\end{array}$ & $\begin{array}{l}\text { B047, B048, } \\
\text { B049, B050 }\end{array}$ & $\begin{array}{l}\text { B47, B48, B49, B50, } \\
\text { B51, B52, B53, B54, } \\
\text { B55, B56 }\end{array}$ \\
\hline
\end{tabular}


Figure 1: Regression to the Mean for Income Per Capita

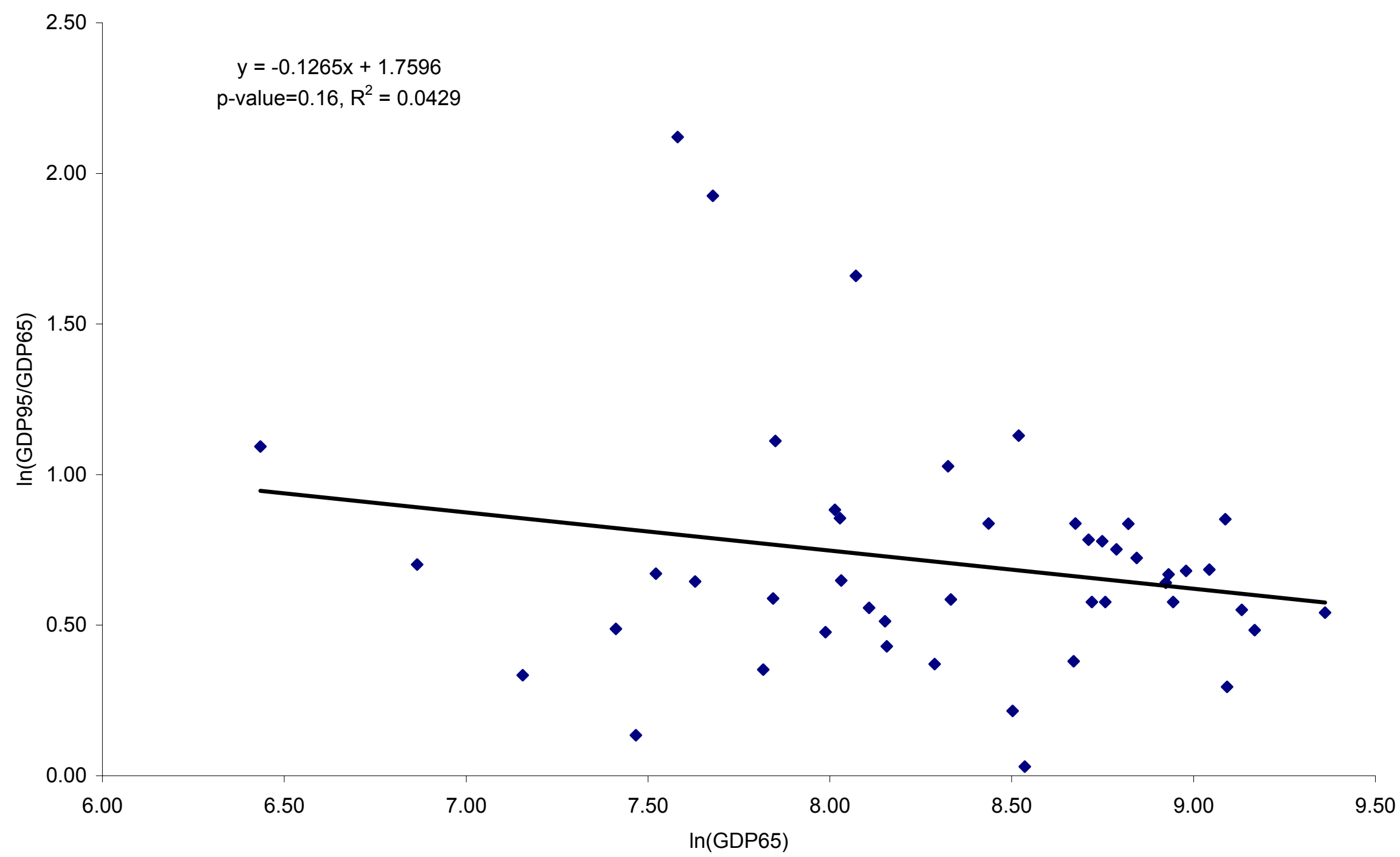


Figure 2: Regression to the Mean for Life Expectancy

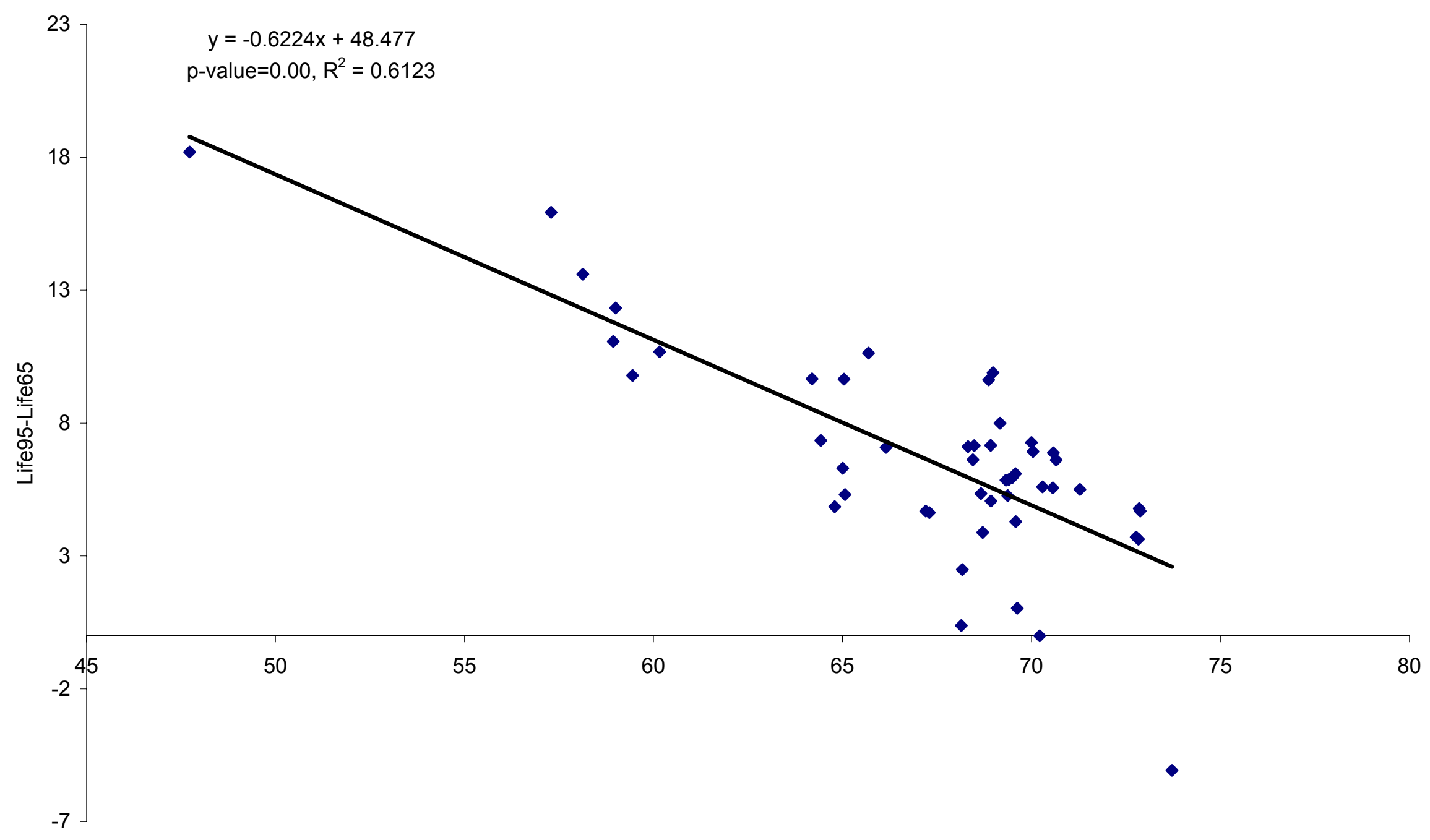


Figure 3: The Changing Relation Between Life Expectancy and Income per Capita

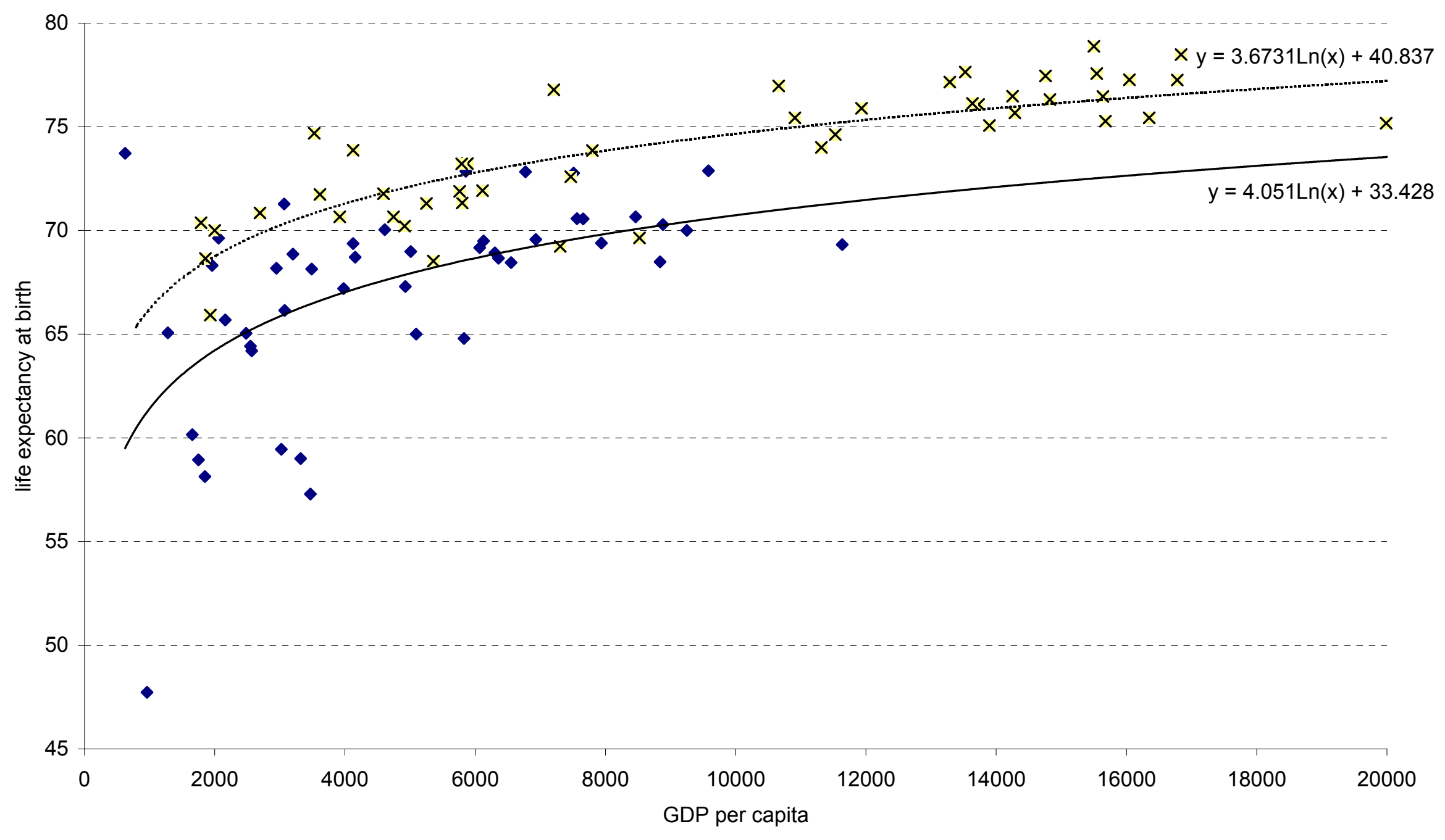

• $1965 \times 1995 \div$ Log. (1965) - . - Log. (1995) 
Figure 4: Regression to Mean fo the Component of Life Expectancy Changes Explained by Changes in Income

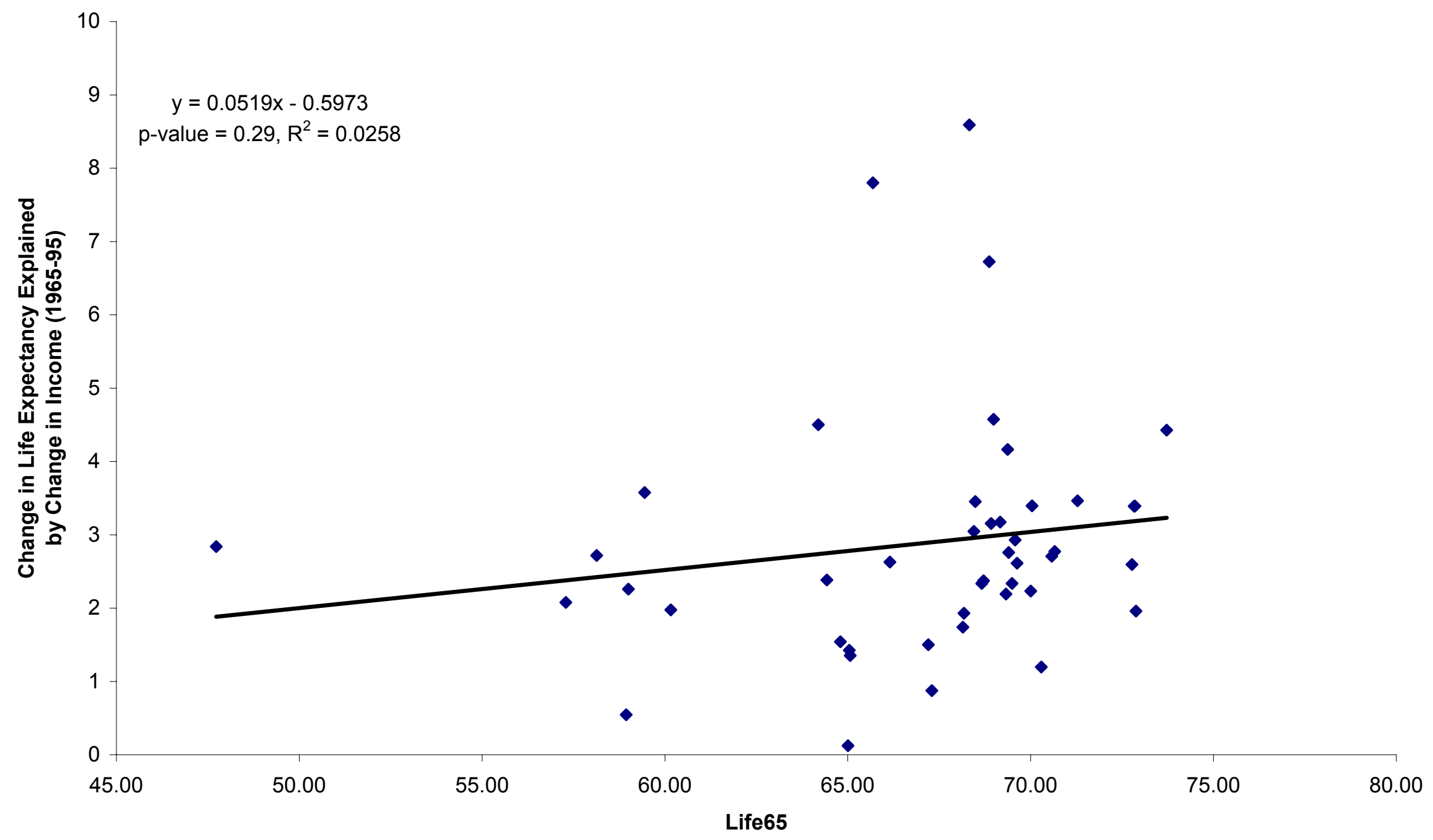


Figure 5: Income Equivalent Compensation for Life Expectancy Gains

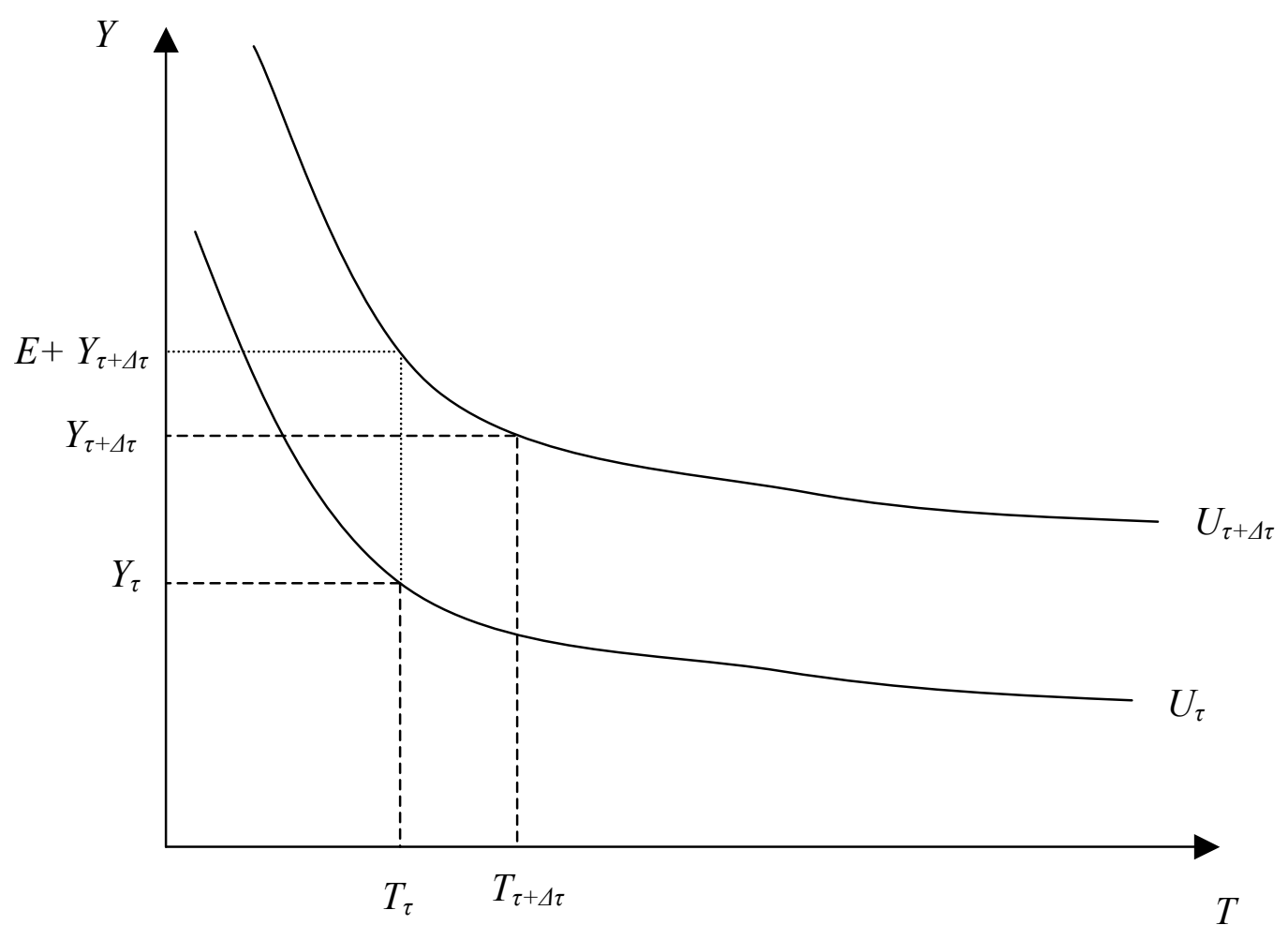


Figure 6: Survival Rate Distributions - Egypt 1965 and Japan 1995

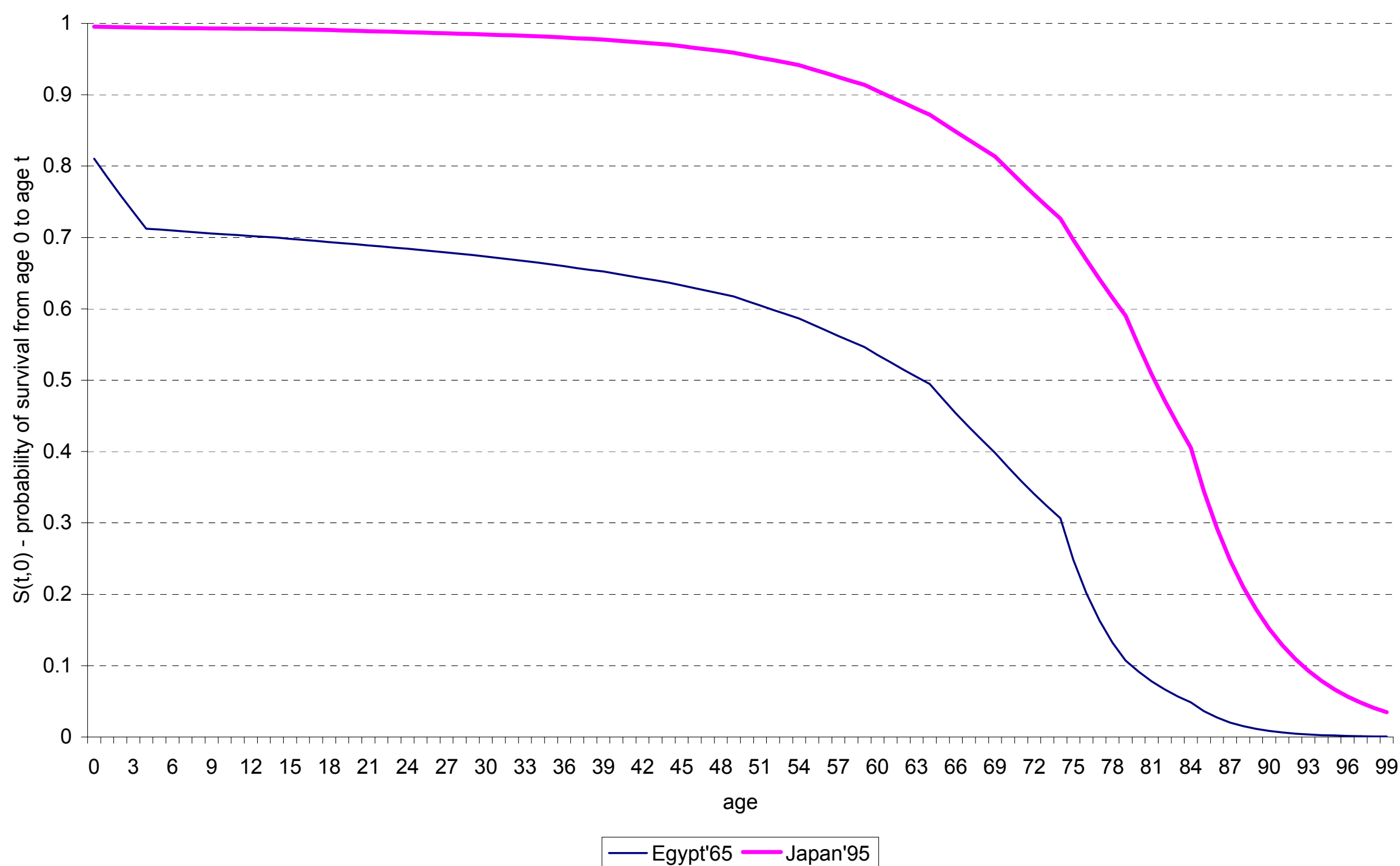


Figure 7: Regression to the Mean for Income Equivalent Compensation

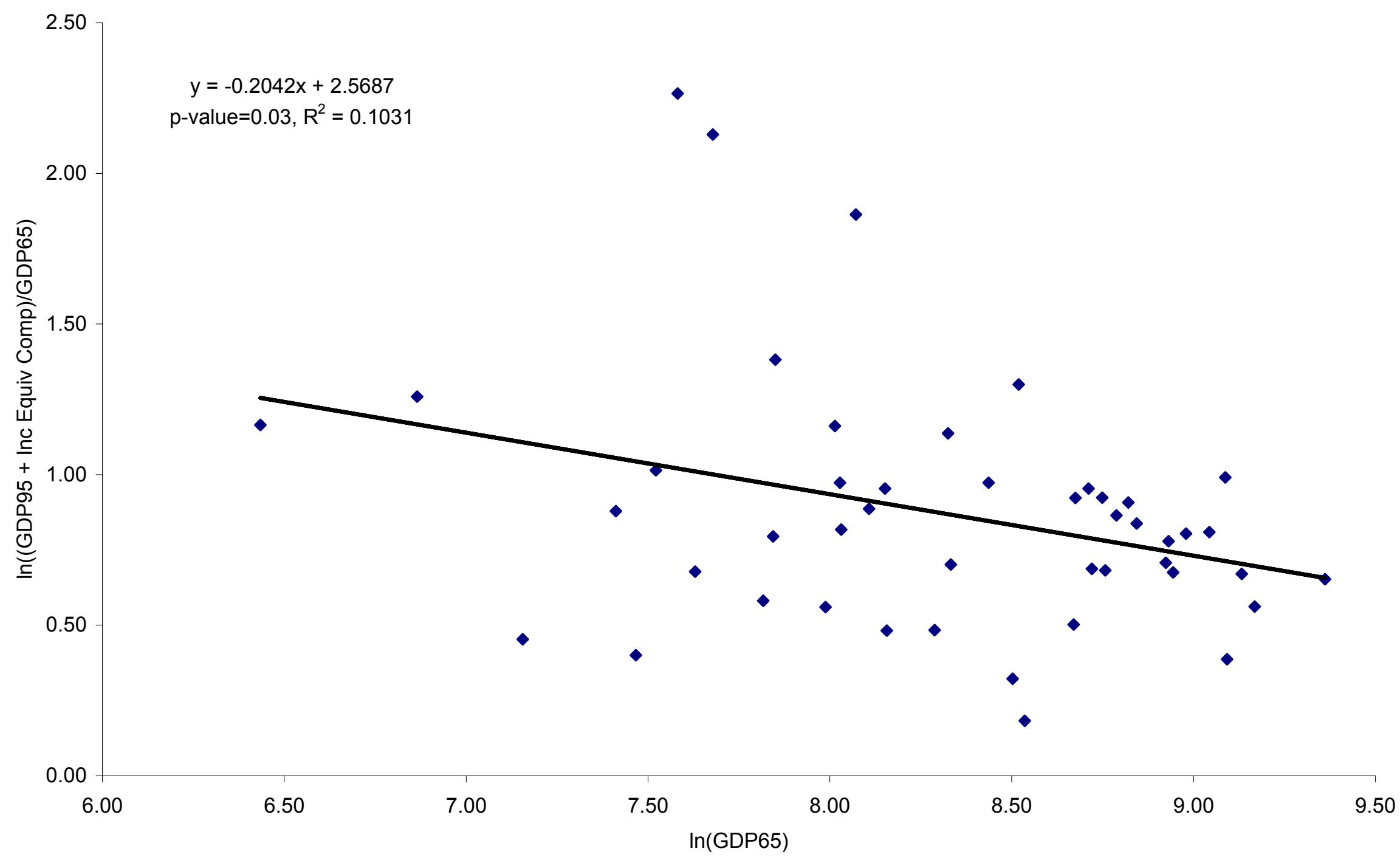


Figure 8: Share of Welfare Improvements due to Longevity Gains

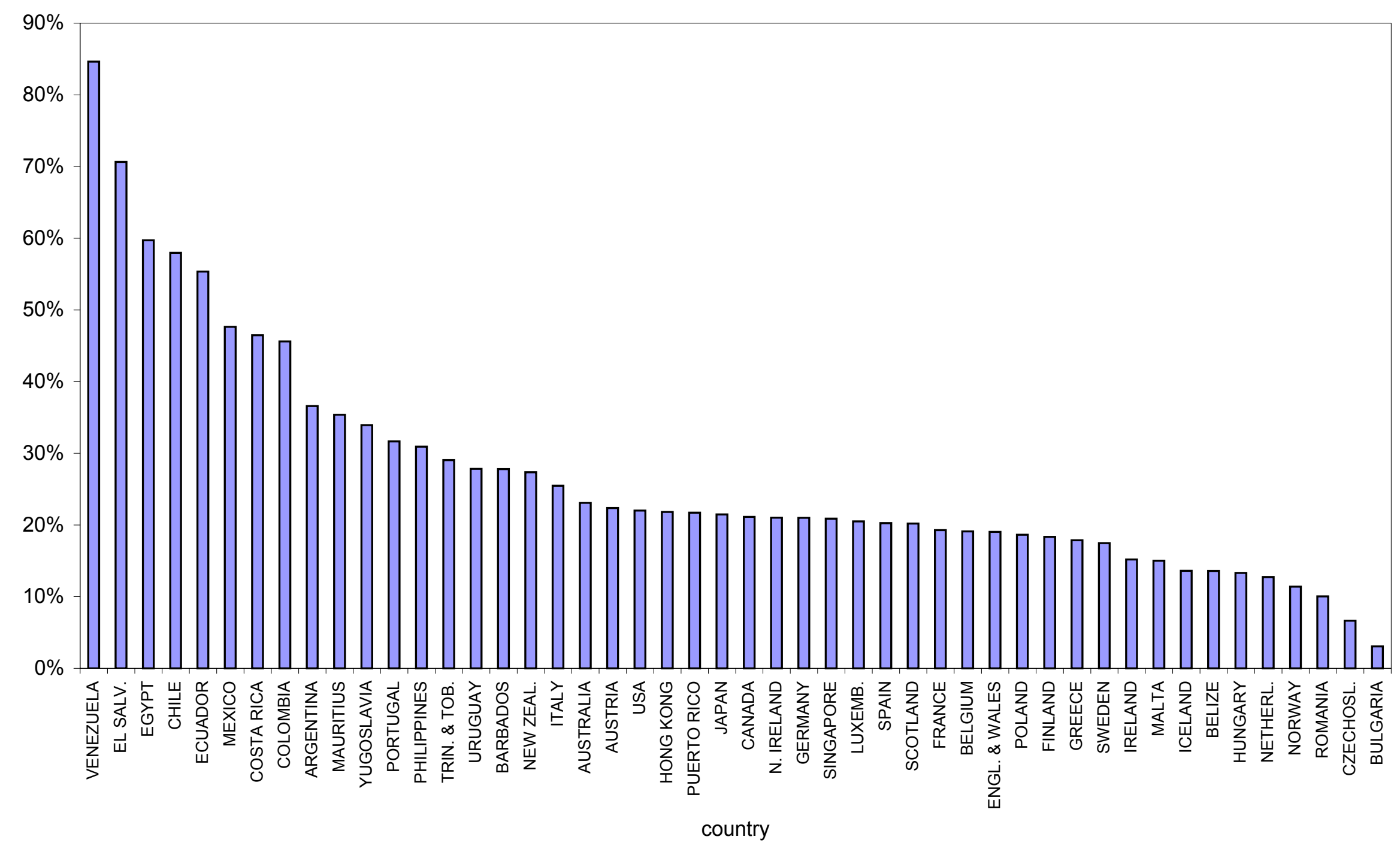

